\title{
Savannah River Technology Center Monthly Report August 1992
}

by

Aiken, South Carolina 29808

This paper was prepared in connection with work done under the above contract number with the $U$. $S$.

Department of Energy. By acceptance of this paper, the publisher and/or recipient acknowledges the U. $S$. Government's right to retain a nonexclusive, royalty-free license in and to any copyright covering this paper, along with the right to reproduce and to authorize others to reproduce all or part of the copyrighted paper. 


\section{AUGUST 1992}

\section{Savannah River}

Technology Center Monthly Report (u)

Westinghouse Savannah River Company Savannah River Site

Aiken, SC 29808

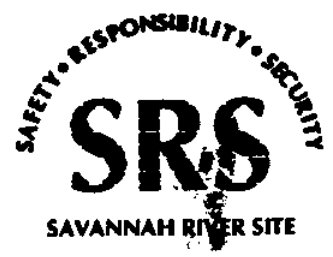

Prepared for the U. S. Department of Energy under contract No. DE-AC09-89SR18035 


\section{DISCLAIMER}

This report was prepared as an account of work sponsored by an agency of the United States Government. Neither the United States Government nor any agency thereof, nor any of their employees, makes any warranty, express or implied, or assumes any legal liability or responsibility for the accuracy, completeness, or usefulness of any information, apparatus, product, or process disclosed, or represents that its use would not infringe privately owned rights. Reference herein to any specific commercial product, process, or service by trade name, trademark, manufacturer, or otherwise does not necessarily constitute or imply its endorsement, recommendation, or favoring by the United States Govemment or any agency thereof. The views and opinions of authors expressed herein do not necessarily state or reflect those of the United States Government or any agency thereof.

This report has been reproduced directly from the best available copy.

Available to DOE and DOE contractors from the Office of Scientific and Technical Information, P.O. Box 62, Oak Ridge, TN 37831; prices available from (615) 576-8401.

Available to the public from the National Technical Information Service, U.S. Department of Commerce, 5285 Port Royal Road, Springfield, VA 22161.

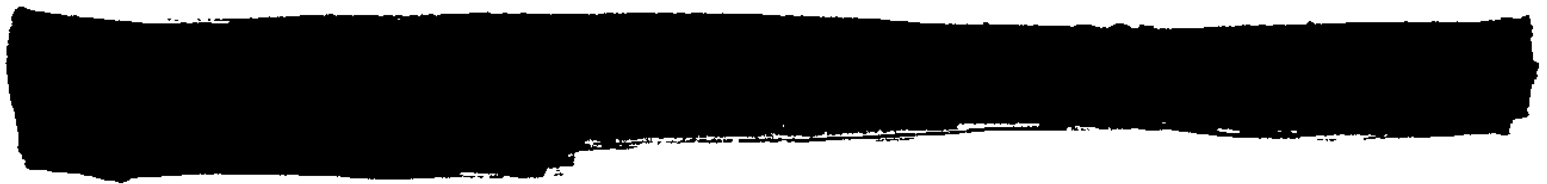




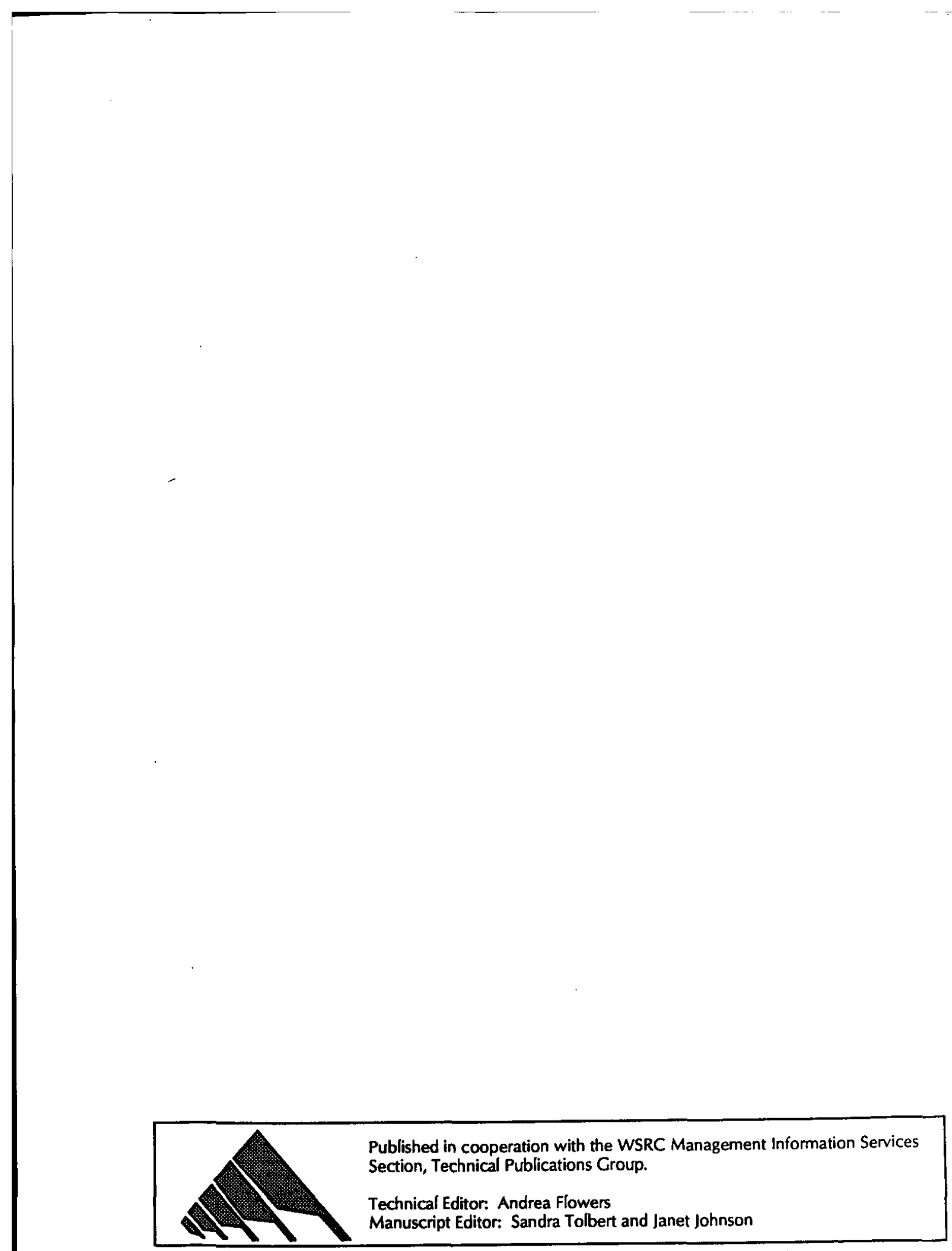


Executive Summary

Reactor 1

Tritium 1

Separations 2

Environmental 3

Waste Management 4

General 4

Progress and Accomplishments

$\begin{array}{lr}\text { Reactor } & 7 \\ \text { Tritium } & 21 \\ \text { Separations } & 29 \\ \text { Environmental } & 33 \\ \text { Waste Management } & 41 \\ \text { General } & 48\end{array}$

Items of Interest

51 


\section{E XECUTIVE SUM MAR Y}

\section{EXECUTIVE SUMMARY}

\section{BEAGTOR}

\section{TRITIUM}




\section{EXECU TIVE SUMMARY}

- Topics from the August 13,1992 kickoff meeting of the JBF Test Program with Sandia National LaboratoriesLivermore (SNLL) are discussed. (page 24)

- A sample of heat treated Pd/k (2 hr @ $1,100^{\circ} \mathrm{C}$ in air) was thermally cycled 4,500 cycles. The particle size distribution was measured after cycling. These results are compared to the cycling results obtained from the $\mathrm{Pd} / \mathrm{k}$ that was heat treated. The comparison shows that the heat treated $\mathrm{Pd} / \mathrm{k}$ is significantly less prone to decrepitation due to thermal absorption/desorption cycling. (page 25)

- Palladium deposited on kieselguhr from a non-chlorine containing palladium salt solution was termed "improved" $\mathrm{Pd} / \mathrm{k}$. Hydrogen and deuterium measurements were completed and the material was transferred to the Materials Testing Facility (MTF) for further study with tritium. (page 27)

- The revised Justification for Continued Operation (JCO) of FB Line was transmitted to DOE-SR. Revisions included a more thorough bounding accident analysis based on $\mathrm{Nu}$ clear Criticality Safety Supplements rather than the nominal batch sizes used in the Safety Analysis Report (SAR). Various comment resolutions were also included. (page 29)

- The consequence analysis in the existing 221-H Canyon SAR is being updated from the ICRP-2 to the ICRP-30 methodology. The newer method yields higher calculated doses. Page changes to the SAR will reflect the new consequence and risk values. (page 30)

- A fuel assembly storage container in the Receiving Basin for Offsite Fuels (RBOF) developed a leak and the upper third eventually split. A relocation device was designed, fabricated, and delivered to RBOF to provide a means to move the canister safely. (page 31)

- On August 21, 1992, at approximately 12:30 PM EDT (16:30 UTC), a magnitude 4.1 (United States Geological Survey) earthquake occurred in the Charleston, South Carolina area. The event was recorded on the WSRC/SRTC seismic network and an automatically triggered accelerograph. At the request of Dr. Talwani of USC-Columbia, WSRC/ SRTC scientists deployed digital event detectors to collect aftershock data. (page 34)

- The final overflight in the series of three was completed on Par Pond. This aerial gamma survey will document the distribution of gamma emitting radionuclides in the exposed surface sediments of Par Pond. (page 34) 


\section{EXECUTIVE SUMMARY}

\section{EMUIRONMENTAL}

- A summary report of biological monitoring and toxicity studies for the F/H Effluent Treatment Facility (ETF) was completed for submittal to the South Carolina Department of Health and Environmental Control (SCDHEC). The results of four years of monitoring studies indicate that the ETF has not adversely impacted the biota of the receiving stream. (page 35)

- $\quad$ SRTC has the capability of estimating distributions of the atmospheric tritium dose received by an offsite individual. (page 35)

- The first draft of the Radiological Assessment Program (RAP) document on Strontium in the SRS Environment was issued for review. (page 36)

- Seven candidate sites for the new Sanitary Landfill were identified for ground-level evaluation and possible geotechnical characterization. The candidate sites were selected based on presence of upward groundwater pressure gradient, reasonable probability of appropriate geological conditions, and the absence of ecological disqualifying conditions. (page 37)

- A helium tracer test was performed to monitor the clay cap at the Dynamic Compaction Test Facility. The results of the helium tracer test indicate that helium migrated through the cap during the compaction operations. The migration appeared to coincide with construction seams and/or potential microfracture zone. (page 39)

- Waste Management requested that a task be initiated to evaluate the effects of mechanical property variations and material degradation on the failure strain for the primary liner of the Type IIIA waste tanks used in the in-tank precipitation (ITP) process. A strain-based failure criterion will be used in conjunction with an evaluation of the waste tank response to a hypothetical hydrogen deflagration accident. The effects of mechanical property variations and material degradation on the primary liner failure strain were evaluated and a knockdown factor (factor of safety) of $\mathbf{1 . 0 5}$ on the primary liner failure strain is recommended. True stress - true strain curves were also developed to support the waste tank structural analysis for the primary and secondary liners. A technical report documenting this work was issued. The remaining work entails estimating the reduction in liner failure strain, relative to uniaxial tensile test data due to multiaxial loading. (page 41) 


\section{EXECUTIVE SUMMARY}

\section{WASTE MANAGEMENT}

- The first draft of the Analysis and Justification Report (AJR) for the Tank Farm OSRs is complete and will be distributed for comment on July 13, 1992. (page 42)

- Benzene sparging tests were completed. They evaluate the rate that benzene is removed from the Late Wash filtrate. Variables tested included the effects of surfynol, temperatures, sparge rates and salt concentrations. (page 43)

- Comments were resolved on the Z Area Safety Analysis Report (SAR). Operational Safety Requirements (OSR) are complete and the report is expected to be issued for DOE review by late September 1992. (page 44)

- The final assessment of the leaching tests, completed in July 1992 shows that Late Wash will have no adverse affect on Saltstone. (page 47)

- A relational data management system for the Ruth Patrick Science center was implemented. The system facilitates the management and scheduling of the center's staff, corporate sponsorships, teaching stations, computer laboratories, teacher workshops, student tours, and other center activities. (page 48)

- Environmental Engineering Section (EES) upgraded the software codes for the ACEC and MERRV remote controlled vehicles and operator console to support wire and wireless communication. (page 48)

- Several report formats were developed to present site demographic data. The method for calculating spans of management was also improved to handle cases where organizational data is incomplete. (page 48)

\section{GENERAL}

- A new method for cleaning vanadium tubing was developed for Lawrence Livermore National Laboratory (LLNL). (page 49)

- $\quad$ EES repaired the drive system in the neutron source assembly for Health Protection (HP) calibrations. (page 49)

- The welding committee approved an engineering standard for welding structural steel. The standard defines what is covered by AWSD1.1 and associated requirements for welding and inspection. (page 49) 


\title{
EXECUTIVE SUMMARY
}

\author{
S.
}

- The elastic-plastic J-integral estimation for circumferential cracks under bending was developed to cover the SRS piping sizes. A flaw stability analysis was demonstrated using a 0.25 inch thick pipe with mean radius 7.5 inches. The properties were selected from the Reactor Materials Program (RMP) baseline materials reported in WSRC-TR-91-10. It is shown that when the applied bending is equivalent to 80 percent of limit load, the crack behavior varies from no growth to unstable growth, depending on the initial flaw sizes. (page 49) 


\section{PR O GRESS AND ACCOMPLISHMENTS}

\section{Her.}

\section{PROGRESS AND ACCOMPLISHMENTS}

\section{BEAGTOR}

\section{Status of Diffusion Theory Codes Certification \\ T.T.Le}

The J80 VAX version of AXLIB4, J80 VAX and IBM versions of GILDA, and J80 VAX and IBM versions of GRIMHX were certified. The certification package of TRIMHX is under technical review and the J80 VAX and IBM versions of TRIMHX will be certified when the certification package is signed. Theory documents, users' manuals, Verification and Validation (V\&V), and benchmarking reports of codes are available at the publication center. The source codes and test problems are listed in the Software Control Management System.

\section{Status of the New-GRIMHX Coding} T. T. Le

Implementation of the new GRIMHX codes for VAX, IBM, and CRAY computers with or without JOSHUA is close to completion. The $k$-effective calculation, buckling search, external source calculation, adjoint calculation, and power flattening options for one point per hex were implemented and test problems were run against the old GRIMHX. The burnup module is being written and options for more than one point per hex will be implemented. The code will be available for V\&V and benchmarking by October 1992.

\section{Alternative Scenarios For Reactor Operation}

N. H. Kuehn

SRS is preparing a White Paper for DOE on alternative modes of operation in which K Reactor is operated after the scheduled standby date. At that time, the technology for operating the reactor will be warehoused. Factors, such as the time to restart from standby and the status of the New Production Reactor (NPR), prompted a review of alternative scenarios that maintain the "operating license" for $\mathrm{K}$ reactor and technical and operating expertise. The Nuclear Engineering Section (NES) is participating in this evaluation with an emphasis on the hydraulic configuration of the reactor and the impact on loss-of-coolant accident (LOCA) limits. Two concepts that can be supported with existing data bases and codes are low power operation of a full charge and a small core with dummy assemblies in the positions where fuels are removed. Both would allow extended operation with one of the Mark 22 cores prefabricated. No significant impacts on limits are expected for either mode. Neither option effectively uses the process water flow.

However, schemes that reduce the total process water flow to match the lower total core power will require extensive testing in reactor tests to provide the empirical data for correlations and to benchmark system hydraulic codes. Although no significant impacts on limits were identified, quantitative verification could not be completed until after the testing and upgrading of the codes. Modifications of the process water piping or pumps would also increase the time needed to resume operation of full cores at full power (i.e. 30 percent of historical) if this mode of operation is required to meet material requirements.

\section{Rig Inspection at Babcock and Wilcox}

\section{A. Nash}

The Mark 22 downflow rig was inspected for internal leakage paths that may explain a lower pressure drop characteristic of an identical upflow section used for NPR. The rig will be disassembled and retumed to SRS.

Tests show that plugging the purge channels increased flow resistance in the downflow rig. Data and miniature videos are available to document conclusions. The estimate that the purge channels bypassed 15 percent of 


\section{PROGRESS AND ACCOMPLISHMENTS}

flow was confirmed. Videos show the location of the slots that are believed to have admitted most of the leakage into the outer purge channel. Comparisons of overall and individual channel pressure drops before and after plugging the purge channels show how plugging appeared to stop 15 percent of the flow. The pitot tubes of the plugged rig provided velocities that, in conjunction with flow areas, provide a mass balance close to that measured by the flowmeters. The result is that models of the rig will produce higher flow instability limits and show more margin for the flow instability (FI) correlation than we are using.

\section{Transient Reactor Analysis Code (TRAC) to Reactor Leak Analysis Program 5 (RELAP5) Conversion Project \\ D. P. Griggs}

The task technical and Quality Assurance Plan for the TRAC to RELAP5 conversion project was approved by the Quality Assurance Section. They were distributed and the 5 -ring $K$ and $L$ Reactors model are operating. NES has one deck that starts from stagnant conditions and ramps up to full $\mathrm{AC}$ flow and $1200 \mathrm{MW}$ power with 5 psig blanket gas. It also has a steady-state deck that takes the final conditions from the ramp deck analysis and maintains steady reactor conditions by means of controllers on tank level, blanket gas pressure, and pumps. Both decks were run successfully. These are the baseline decks for the LOCA-FI and loss-of-pumping accident (LOPA) analyses to be performed and compared to existing tracking radioactive atmospheric contaminants (TRAC) results.

With the help of Idaho National Engineering Laboratory (INEL), a stagnant initial condition was set up in our 5-ring L-Reactor ramp deck and the analysis to provide full $\mathrm{AC}$ flow, zero power initial conditions were successfully performed. L Reactors' steady-state deck is also successfully operating. These decks are the baseline for benchmarking work.

\section{Type Q Septifoil Analyses}

\section{G. P. Flach and M. A. Shadday}

NES completed a one-dimensional septifoil model, a model of the secondary flow in the septifoil muff, and guide tubes with the proposed modified partial length control rods. Benchmarking of the model results compare well with the Heat Transfer Laboratory data. The model results for freeboard have a non-conservative bias of a few inches. When these and the results of the secondary flow model analysis are corrected, they will be conservative. The average bias is about -9 inches. These comparisons give confidence that the corrected analytical results conservatively predict freeboard.

On the secondary flow model, the upward flows through the muff and partial rod extension tubes are caused by the stagnation of the septifoil axial flow in a complex multi-dimensional flow field in the ten inch region between the slots and the bottom guide plate of the muff. The multi-dimensional flow field is not explicitly modeled. Instead, the septifoil flow is assumed to stagnate isentropically on the bottom surface of the lowest guide plate. This is a bounding value for the supply pressure for secondary circulations in the muff and through the extension tubes. This analysis is conducted in support of the control rod redesign and review process. The results will be used to confirm that the new partial rod design will not cause an overflow in K Reactor under any circumstance.

\section{Review of Recent Aerosol Filtering Studies}

T. A. Long and P. R. Monson

To characterize the filter compartments in the Airborne Activity Confinement System (AACS) for modeling purposes, the Safety Analysis and Engineering Section (SAES) Group contracted Vince Novick of Argonne National Laboratory to perform aerosol mass loading experiments on SRS filter materials. Results from the final tests are documented in WSRC-RP-92-582, "Characterization of the Airborne Activity Confinement System Prefilter Material (U)", and WSRC-RP-92-645, "Effect of Particle 


\section{PROGRESS AND ACCOMPLISHMENTS}

Hygroscopicity and Ambient Humidity on the Mass Loading Capacity on the SRS high efficiency particulate air (HEPA) Filter Material (U)".

Data from the prefilter experiments indicate that the prefilter (sometimes referred to as the moisture separator) collects solid and liquid particles. The collection efficiency is 100 percent for particles larger than four microns and drops to zero percent for particles smaller than .1 microns. While the pressure drop across the prefilter material is essentially zero for liquid particles, solid and combined solid and liquid particles cause the pressure drop to increase linearly with mass loading for a HEPA filter. Data from the hygroscopic tests indicate that aerosol particles, which are capable of absorbing moisture from humid air, can dissolve and the resulting liquid particle loading on the HEPA filter material causes an exponential increase in pressure drop with mass loading.

\section{Analysis of the Fast Transient Effect on Non-LOCA Flow Instability Limits}

\section{S. B. Rabin}

The fast transient effect is the difference between the FI limit derived via steady state conditions and the limit derived via transient conditions. While FI first occurs in an assembly, the FI limit is based on the assembly effluent temperature. The thermal delay is known as the fast transient effect. Both the transient analyses and the non-LOCA FI methodology accounts for the fast transient effect.

Several options are available for increasing the Non-LOCA FI limits by considering the fast transient effect in one method. The first option involves using the FI limit equation with an additional temperature penalty adjustment for the "worst case" non-LOCA fast transient effect while removing the fast transient penalty from the transient analyses. The result is a three percent margin gain in the LCRC transient. The second option involves eliminating the fast transient penalty from the FI limit equation and continue using the fast transient penalty in the transient analyses. This option results in a net margin increase of about 0.3 percent and is not recommended. The last option is the next update of the MARY point kinetics code that will include an adjustment for a more realistic fast transient penalty. The effect on margin to FI will be investigated when the updated MARY is available.

\section{Severe Accident Analysis Program Summary (SAAP)}

T. E. Britt, M. L. Hyder, and T. A. Long

The SAAP includes experimental and analytical studies aimed at characterizing postulated severe accidents for the SRS reactors. The goals of the SAAP include:

- developing an understanding of severe accidents in the SRS reactors adequate to support safety documentation of the reactors such as the Safety Analysis Report (SAR) and the PRA

- providing the tools for evaluating existing or proposed safety related equipment for the SRS reactors

- providing the bases for development of accident management procedures for the SRS reactors

- developing and maintain a body of knowledge, including documents, computer codes, and cognizant engineers and scientists, such that issues related to reactor accidents can be authoritatively resolved

- exporting the knowledge and technology developed for severe reactor accidents to non-reactor areas with the potential for severe accidents.

The SAAP was instituted in 1987 and has generated a large body of experimental information with regard to mobilization of radioactive materials released from core components, accident progression phenomena, such as fuel melt relocation, energetic phenomena, such as steam explosions, hydrogen explosions, molten core concrete interactions, recriticality, and the response of the reactor confinement system to accident phenomena. The experimental data are being incorporated into various computer codes available for severe accident analysis such as Statistical Analysis System-Heavy Water Reactor (SASHWR), MELCOR/SR, and SCDAP/RELAPS. The SAAP evaluates experimental data and warehouses the information by generating a series of integrated studies of accident phenomena starting in late 1992. 
PROGRESSA NDACCOMPLISHMENTS

\section{Level 1, Revision 1 Internal Events PRA Sequence Analysis}

\section{S. P. Tinnes}

Quantification of Revision 1 of the K-Reactor Level 1 Internal Events PRA is complete. The PRA is specific to $K$ Reactor and its physical state in June 1992 operating at 30 percent power. It includes the complete spectrum of potential "internal initiators". Primary and secondary LOCAs are included for different size leaks and leak locations, Loss-of-Heat-Sink (LOHS) initiators, Loss-ofRiver-Water (LORW) initiators, and transients (e.g., flux, flow, Loss-of-Normal-Power, etc.). The CAFTA family of software (IBM compatible) is used for fault and event tree modeling and sequence quantification.

The severe core melt frequency (SCMF) point estimate from internal initiating events for the 1992 configuration operating at 30 percent power is $1.4 \mathrm{E}-5$ per reactoryear, compared to $2.1 \mathrm{E}-4$ per reactor-year for the 1987 reactor configuration operating at 100 percent power. More than $\mathbf{3 0 0}$ different sequences from different initiating event classes contribute to the result. The analysis required seven iterations. Following internal and external review, it is expected that additional iterations will be made, but the total SCMF will not change significantly.

The largest reduction in SCMF from the 1987 reactor configuration (100 percent power case) to the 1992 reactor configuration ( 30 percent power case) is with the primary and secondary LOCA initiating events. These reductions are caused by the installation of new safety systems designed to cope with these accidents, improved emergency operating procedures, improved reactor operator training, better defined Emergency Core Cooling System (ECCS) and shutdown system success criteria, based on "state-of-the-art" technology, and significantly less stringent success criteria resulting from limiting reactor power to 30 percent.

The dominant Level 1 PRA sequences that lead to core damage are as follows:

- a bellows break in the Process Water System resulting in a leak $>1800 \mathrm{gpm}$, failure to isolate the leak, and failure to inject emergency cooling
- a large Cooling Water System pipe break, failure to isolate the leak, and failure to inject emergency cooling (i.e., LOPA)

- a transient with failure to shut down

- a Loss-of-Heat-Sink (process water or cooling water side) and failure to inject emergency coolant

- a Loss-of-River-Water initiator with failure to maintain the 186 basin level

\section{DOE Review of Level 1, Revision 1 Internal Events PRA \\ S. P. Tinnes}

DOE designated INEL (H. J. Reilly, et. al.) DP-62 as the independent reviewer for Revision 1 of the K-Reactor Level 1 Internal Events PRA. The PRA is specific to K-Reactor and its physical state in June 1992 operating at 30 percent power. On July 30, 1992 Reilly met with NRTSC-STS Level 1 PRA group personnel to formalize the review plans. The Level 1 PRA status and recent quantification results were discussed and a tentative detailed review schedule was arranged. DOE will not begin review until documentation drafts (with supporting Calc-Notes) for the Level 1 PRA are written and reviewed by WSRC. It is expected that the detailed DOE review will begin in October 1992 and will continue through end of the year.

DOE designated Los Alamos National Laboratory (LANL) (K. Sasser, et. al.) DP-62 as a dependent reviewer for the Level 1 internal Events PRA. LANL will provide assistance to WSRC in the PRA effort where required. A tentative Level 1 PRA review meeting with LANL representatives is scheduled at SRS during the first week in September 1992.

\section{Cooling System Success Criteria}

\section{R. T. Bailey and D. A. Kalinich}

In the Level 1 Savannah River Site PRA, the performance of the Emergency Cooling System (ECS) during various accidents is determined by a set of "ECS success criteria". These criteria identify the cooling system's operational configurations required to prevent core melt 


\section{PROGRESS AND ACCOMPLISHMENTS}

for each accident in question. The success criteria, utilized in Rev. 0 of the Level 1 PRA, were analyses performed prior to 1987 and an effort to update them for the first revision is under way.

Calculations were performed to facilitate this update for LOCAs and LOPAs with RELAP5/MOD2.5 and TRAC-PF1/MOD3. INEL and Risk and Source Term Technology (R\&SST) personnel handled the majority of the LOCA calculations with RELAP. The bulk of the LOPA work was relegated to TRAC (Science Applications International Corporation). R\&STT, using RELAP, performed an investigation of certain flow reduction transients (without scram).

Based on the results of these calculations, the final set of updated success criteria was issued (see SRL PRA-920175). Draft Calc-Notes, documenting the calculations performed, are nearing completion.

A prototype manual control module (MCM) was tested in the control rod drive system mockup. The prototype was demonstrated at a design review and given to Reactor Engineering for testing. The delivery achieved a project milestone two weeks ahead of schedule. Equipment Engineering is awaiting capital project funding to proceed with the fabrication of twelve units.

\section{Single Failure Analysis (SFA) Task B. J. Shapiro}

The Cooling Water System (CWS) SFA draft is close to completion. The Draft was scheduled to be completed in September, 1992 but it will be completed approximately one month early. This analysis includes a formal Failure Modes and Effects Analysis of the CWS and its auxiliaries. Following internal comment incorporation, the package will be submitted to Reactor Restart Division (RRD) for review.

The draft of the Preliminary LOPA and LOCA scenarios of the Cooling Tower Upgrade was completed and issued for review and comment. The report outlines the 186-Basin Level drop and timing required by operators and equipment to mitigate the event for these scenarios. The report will be issued when comments are incorporated.
The first draft of the SFA package for the Building CWS was submitted for design verification. The reviewers' comments are being incorporated. The SFA draft package is scheduled to be completed during the week of August 24, 1992. The CWS is a safety support system primarily used to provide an alternative means of supplying Effluent Cooling Water to the 186-Basin for the long-term safe shutdown of K-Reactor.

\section{ROMS Support}

J. M. Tarpley and Jim Pearce (RE)

The General Micro-Systems (GMS) board is an intelligent IEEE-488 controller that is in the final stages of qualification. It serves as the interface between the data acquisition systems and the computers. The acquired temperature and pressure operating data is channeled from the Neff Instruments scanners to the Virtual Memory Eurocard-based processors through this interface. Data buffering and filtering will be performed at this process point prior to analysis for reactor operating limit compliance.

The failed V17 board was returned to the vendor for repairs. A connector will be substituted on the GMS breakout board to meet our mounting and rigidity requirements. A purchase requisition is being prepared to meet the ROMS fabrication requirements and for submission upon the direction of Reactor Engineering (RE).

\section{GRIMHX Predictions of Axial Power Shapes with 3-D Depletion Modeling} R. L. Frost, C. Boman, and K. A. Niemer

The accuracy of GRIMHX axial power shape modeling was questioned after the completion of the Reactor Startup Procedure 90-007-12. Operators were required to move partial rods in gang 1 from 800 to 850 veeder units. Predictions based on GRIMHX indicated a reactivity decrease should occur when the partial rods were inserted, requiring full rods to be withdrawn to compensate. Instead, a reactivity increase was obtained. The test showed that the GRIMHX predicted axial power shape was different from the one present in the reactor. A possible cause of the 


\section{PROGRESS AND ACCOMPLISHMENTS}

inaccurate shape prediction is axial xenon buildin that was not accounted for in the original GRIMHX calculations. Using Reactor Monitoring System data, a GRIMHX model that accounted for axial xenon buildin was produced. The analysis showed that axial depletion effects were not the cause of the discrepancy between observed and GRIMHX calculated axial power shapes near the beginning of the cycle.

\section{GRIMHX Predictions of Xenon Worth Using 3-D Depletion Modeling \\ R. L. Frost, C. Boman, and K. A. Niemer}

During the Power Ascension and Test Program, numerous opportunities arose to determine xenon worth associated with an increase in reactor power and compare it to predicted values. RE typically determines "observed" $x$ non worth by finding the difference in control rod worths between the starting and ending power, allowing sufficient time for xenon to achieve equilibrium. The rod worths used in the calculation are determined using GRIMHX. Predicted xenon worth, associated with a given change in reactor power, is determined using the $X C P 22$ code, which relies on GLASS-produced fewgroup cross sections and user-entered radial weighting functions. When reactor power was raised from $79 \mathrm{MW}$ to $116 \mathrm{MW}$ on June 26 , 1992, an "observed" xenon worth of 782 pcm was calculated (the prediction was $558 \mathrm{pcm}$ ). Using the seven layer Mark 22 model and the core-following methodology described in the above report, the beginning and ending reactor states were modeled. The value of $k$-effective between the two states should be the same, since the reactor was critical before and after the increase in power. However, GRIMHX predicted a difference of $222 \mathrm{pcm}$ between the states. Since the GRIMHX prediction of axial power shape is questioned, a parametric study of k-effective versus partial rod position was performed. It was found that when the partials were moved from their nominal position of 800 veeder units to 835 veeder units, the $k$-effective at the beginning and ending states was identical. With the partials in the new position, a xenon reactivity worth of $584 \mathrm{pcm}$ was calculated. This value agrees with the value predicted by XCP22. It shows that the discrepancy in xenon worth was caused by an error in the original methodology used to determine the "observed" worth, not in the methodology used in predicting xenon worths.

\section{Axial Distribution of Fuel and Target Material in Mark 22 Assemblies R. E. Grove}

Discrepancies between predicted and observed axial flux shapes were noted historically and during the recent K-14.1 startup and power ascension test program. The Applied Physics Group is investigating several possible causes for the discrepancies. Previous analyses indicate that because of general agreement in the results of independent computational methods, the discrepancies may be due to the axial model rather than the computational method. As a result, Applied Physics is re-examining the axial model. As a part of this review, the axial distribution of neutronically important materials within the core is being investigated.

A Mark 22 assembly contains four concentric tubes: two aluminum-lithium target tubes and two aluminum-uranium fuel tubes. The tubes are fabricated in a co-extrusion process. The co-extrusion process produces tubes in which the axial distribution of fuel or target material is characterized by a full core region and transition regions on either end of the tubes. Manufacturing specifications limit the axial variation of the contents in the full core regions in the tubes. The Nuclear Test Gage (NTG) measures the contents of each tube to verify that specifications are met. The transition regions on either end of the tubes (called core ends) are characterized by a transition from a full core thickness of the fuel or target material to an aluminum alloy tube that contains no fuel or target material. Manufacturing specifications limit the axial full core length from end to end. A fluoroscope measurement locates the core ends in each fuel tube and verifies that specifications are met. An eddy current measurement is used for target tubes.

The axial models used for general physics analysis typically apply gang average lineal contents for each tube type uniformly over the central (axially) portion of the 


\section{PR O G R S S A ND ACCOMPLISHM ENTS}

reactor core. Each tube is modeled with the nominal core length and nominal lineal contents. Preliminary scoping calculations indicated that variations of lineal contents and core lengths within the envelope of manufacturing specifications may account for some of the observed discrepancies in the calculated axial flux profile. The current effort is primarily focused on developing a physically reasonable preliminary model of the true axial distribution of fuel and target materials in the different tubes. A sampling of information on the measured axial distribution of material within the fuel and target tubes was obtained. Detailed axial NTG data and full core lengths were obtained for each of the four tube types in the 108 Gang I assemblies in the K14.1 charge. Results of routine destructive tests on 12 of the four tube types were also obtained.

The data are being analyzed and synthesized into a preliminary axial model that will be used in physics analysis codes to determine the effects of axial material non-uniformity within manufacturing specifications. Concurrently, the GRIMHX code is being revised to enable a more convenient variation in the axial profile and a new code is being developed to permit convenient scoping calculations.

\section{The Effect of Axial Burn-up and Flux Shapes on the Single Rod Withdrawal Accident \\ G. R. Cefus}

A study investigated the validity of ignoring the axial variation of Mark 22 fuel material contents due to burn-up in control rod accident safety analyses. In the past, each Mark 22 axial layer in the GRIMHX computer code was modeled with the same contents as every other layer (i.e., no burn-up). During actual reactor operation the characteristic axial flux shape of a Mark 22 charge causes non-uniform burn-up in the fuel, therefore, a non-uniform material content distribution results. The results of this study indicate that a significant difference in the calculated severity of the Single Rod Withdrawal (SRW) accident will be observed when fuel burn-up is considered.
These results have no adverse effect on the SRW accident safety analyses performed for the K-14 Mark 22 charge because the planned discharge exposure will be low, resulting in relatively insignificant axial variations due to burn-up.

An additional objective of this study was to evaluate the efficacy of bounding the allowed core axial flux shape by the Roof-Top-Ratio. Results indicate that limits placed on this parameter should be adequate for cosine and saddled axial shapes.

\section{Analysis of Observed and Predicted Critical Positions}

\section{R. L. Frost}

In the initial phase of the reactor test program, full control rod critical positions were found for three partial rod positions: 700,800 , and 950 veeder units. These critical position determinations were made before leaving the zero power phase, so fission products are negligible. GRIMHX calculations of the critical positions resulted in values of k-effective that differed over a range of $64 \mathrm{pcm}$. If one were to use the GRIMHX predicted value of k-effective resulting from the critical position calculation at 800 veeder units as a bias to calculate critical positions with partials at 700 or 950 veeder units, large errors in critical position would result. Since GRIMHX axial power shapes were questioned, a parametric study was performed by maintaining full length control rods at their critical position while varying partial control rods from -40 to +40 veeder units off their true position. By fitting the data and minimizing the difference function, it was found that if the partials are modeled as being inserted +36 veeder units more than they actually are, the $k$-effective resulting from each critical position calculation agree within $13 \mathrm{pcm}$. This calculation is independent from the calculation performed for the xenon worth study described above, but the results are an identical partial rod insertion bias. This indicates that the inaccuracies in GRIMHX axial flux shapes are caused by a systematic error in the model. 
PROGRESS AND ACCOMPLISHMENTS

\section{Gang Partial Rod Drive Event}

\section{R. L. Frost, C. Boman, and K. E. Hammer}

The Gang Partial Rod Drive event was analyzed. During the routine positioning of partial-length control rods in gang 3 on July 27, 1992, the partial rods continued to drive into the reactor after the operator released the controlling toggle switch. In response, the Applied Physics Group analyzed the gang partial rod drive event. This accident scenario was not considered in the analysis for Chapter 15 of the Safety Analysis Report (SAR). The intent of the analysis was to find the conditions where the previously analyzed gang rod withdrawal (GRW) accident bounds the gang partial rod drive accident. Once these conditions are determined, a revision of the Technical Specifications or an administrative procedure can be used to ensure that reactor operations remain within the analyzed safety envelope.

The gang partial rod drive event is bounded by the gang rod withdrawal accident when the driving gang contains weak partial-length control rods in every cluster, or double partial-length rods in every cluster shadowed by at least $\mathbf{1 0 0 0}$ veeder units of full-length rod. It is not bounded by the GRW event when the driving gang contains unshadowed (no full-length rods) double partial-length control rods in every cluster. With unshadowed double partials in every cluster, the maximum reactivity addition rate exceeds the GRW maximum reactivity addition rate by at least fifteen percent.

\section{LOCA Maximum Emergency Cooling System (ECS) Flow Rates D. A. Burge}

NES calculated the heat exchanger discharge maximum ECS flow rates for AC and DC flow. The results augment previous analyses on the response of the system to maximum ECS flow following breaks at major locations. The estimated rates are greater than the rates following a plenum inlet break, but do not exceed previously reported maximum rates following a pump discharge break. The ECS rates and the moderator tank level responses, following the heat exchanger break, have similar characteristics observed in pump discharge break and plenum inlet break responses, as expected. However, the tank refills above the top shield for the heat exchanger discharge break without overflow via the u-tube, whereas overflow does occur for the plenum inlet break under maximum ECS flow conditions. Tank levels are markedly different than those observed for limits analyses of minimum assembly flow.

\section{K-Reactor Support}

\section{J. C. Whitehouse}

RRD requested that NES support flow measurements in $\mathrm{K}$ Reactor immediately after reactor testing. Six ultrasonic flowmeters and supporting equipment were obtained to measure $A C$ and DC flows and justify the position that the Bingham pumps did not degrade, thereby obviating the need for a scheduled pump tear down.

\section{SAR Chapter 15 Training}

W. M. Massey

Final preparations are complete for the Reactor Department training seminars on the SAR Ch. 15 analyses. The seminars began the first week of August 1992 with a six hour session each Monday and will run for nine weeks. They cover LOCA (NES) and non-LOCA (STS) events and representatives from both organizations will deliver presentations. Approximately 20 people will attend each class, including representatives from Reactor Engineering - Design, Thermal-Hydraulics and Technical Support, Reactor Department - shift technical advisors, RTAP and Facility Safety Evaluation Section (FSES) and SRSPO.

NES personnel assisting in the presentations are W.M. Massey, L.D. Koffman, N. H. Kuehn, and A. A. Zagrodnik.

\section{Corrosion of Aluminum Clad Fuel and Target Alloys in the K-Reactor Disassembly Basin}

\section{J. P. Howell}

Long-term corrosion tests are underway to evaluate the corrosion behavior of aluminum fuel and target cladding alloys in the K-disassembly basin environment. In March 1992, after 107 days of storage in the K-reactor basin, Type 1100 aluminum "tube ends" and Type 8001 aluminum "tube ends" were removed from the basin and metallurgically evaluated to determine their corrosion 


\section{PROGRESS AND ACCOMPLISHMENTS}

behavior. Analysis of these inert components showed that the 8001 alloy experienced pitting corrosion to a maximum depth of 59 mil and the 1100 alloy had pit depths of $23 \mathrm{mil}$. The depth of pitting on the 8001 samples was about twice the cladding thickness of the 8001 alloy ( $30 \mathrm{mil}$ ). Pits on the 8001 alloy were fewer in number but larger in diameter and deeper than the 1100 aluminum.

In March, additional components were loaded on insulated aluminum fixtures and suspended about three feet beneath the K-basin water surface. In addition, a number of components continued their exposure to the basin environment. On June 2, 1990, components with 75 and 182 days exposure were removed from the basin. Components were brought back to SRTC and color photographs document the corrosion product on the individual components. The random nature of the conosion process can be seen from the photographs that show no pits on the outside of 1100 components exposed for 182 days and more than 50 pits on the inside of the same tubes.

Other $\mathbf{1 1 0 0}$ alloy tubes exposed for $\mathbf{7 5}$ days had as many as 80 pits on the outside of the tube and no pits on the inside. The 8001 aluminum clad fuel component generally had between 5-6 pits that were about $1 / 8$ to $3 / 8$ inches in diameter and appear to have a maximum depth exceeding the $30 \mathrm{mil}$ clad. Metallurgical evaluation of these specimens is underway to determine actual pit depths.

The water chemistry for the Vertical Tube Storage (VTS) section of the K-basin shows that the basin generally operated within limits during this six-month period of time. The $\mathrm{pH}$ was slightly above the $\mathrm{pH} 7.9$ limit from December 1991 to January 1992. The chloride ion content remained in the 7 to $9 \mathrm{ppm}$ range and the conductivity of the water remained from about 175 to $185 \mathrm{mmho} / \mathrm{cm}$. Recent tests indicate that significant pitting corrosion occurs in $\mathbf{7 5}$ to 180 days, which suggests that the basin water is aggressive even though the water set chemistry for operation is within limits. Normally irradiated material stays in the basin for less than one year and rarely more than two years before processing by Separations. With the canyons currently shutdown, fuel has remained in the basins for more than four years. Long-term corrosion of the aluminum can lead to breach of the clad followed by release of fission products to the basin.
The Receiving Basin for Off-site Fuel (RBOF) successfully stores aluminum clad fuels for more than ten years without failure. Examination of the differences in operations of this basin and the reactor disassembly basin shows that impurities, such as chloride, are controlled in the parts per billion (ppb) range compared to parts per million (ppm) in the disassembly. Perhaps, the most important consideration, is that the conductivity, indicative of cations and anions, is controlled to less than 1.0 $\mathrm{mmho} / \mathrm{cm}$ in RBOF (vs. $150-200 \mathrm{mmho} / \mathrm{cm}$ in the $\mathrm{K}$-basin). This is achieved by continuous operation of the deionizers. RBOF also uses. aluminum storage racks, whereas stainless steel hangers are used in plant operations. This eliminates the potential for galvanic corrosion, which is suspected to have played a role in the past.

Efforts are underway in the plant and SRTC and to improve the chemistry of the K-basin and its operation. Equipment is being developed to vacuum the basin floor to remove the sludge and residue collected over the years of operations. Water, sludge, and concrete samples were received from $\mathrm{K}$ Reactor and are being analyzed. Some of the basin water was purged and deionizers will soon operate in a more continuous mode to reduce the conductivity of the water. Additional deionizers from a commercial source may be brought in to expedite the clean-up process. Purchase of aluminum or insulated hangers is also being considered. These efforts should enhance the storage performance of new assemblies placed in the basin and should slow the corrosion of the assemblies stored in the basin. The ultimate solution to the corrosion problem is to startup the Separations facilities and work off the storage inventory.

\section{Primary Water System (PWS) Expansion Joint Acceptance Criteria} W. L. Daugherty, R. F. Miller, and N. K. Gupta

Efforts to develop acceptance criteria for in-service inspection of expansion joints are continuing. Efforts to develop and verify a computer code for fatigue crack growth predictions continue. This code will be benchmarked against vendor fatigue test data. Finite element-based calculation of the stresses during the vendor 


\section{PROGRESS ANDACCOMPLISHMENTS}

fatigue test were completed. Finite element models are also being developed for evaluating the effect on local stresses of dents. These results will be used to develop acceptance criteria for denting.

An additional effort is in progress to develop specific acceptance criteria for degradation of the internal flow sleeves. These criteria will be simple, since the sleeves in the smaller expansion joints are designed to be replaceable.

Structural integrity analysis for the larger expansion joint sleeves is complete. Structural analyses, using the ABAQUS finite element computer code, were performed to analyze the sleeve response under static and dynamic loadings. The static analyses include pressure and gravity loadings. The dynamic analyses include seismic interaction between the sleeve and the expansion joint end flange and flow induced vibrations. A flaw evaluation analysis was performed to develop acceptance criteria for any indications found during in-service inspection.

Seismic interaction analyses show that the free end of the sleeve will be deformed due to interaction with expansion joint end flange under the worst seismic loading $(0.2 \mathrm{~g} \mathrm{SSE})$. However, the increase in the annular flow area is approximately $14 \mathrm{sq}$. in., thus limiting the total annular flow area to less than 55 sq. in. specified for the new expansion joints.

Flaw evaluation analyses show that for seismic loading conditions, throughwall axial flaws up to 2.5 inches long will not become unstable. Any growth in the highly localized tensile stress areas will be arrested in the surrounding compressive stress areas.

Flow-induced vibration analyses show that due to low flow velocities, there will be no fluid-structure instability. Also, since the sleeve is a smooth cantilever pipe without any branch connections, turbulence in the incoming flow will not cause flow-induced vibrations.

\section{PWS Integrity for Extended Reactor Operations \\ J. K. Thomas, N. G. Awadalla, R. L. Sindelar, W. L. Daugherty, D. M. Barnes, and G. E. Mertz}

DOE is considering running $\mathrm{K}$ Reactor for an extended period of operation after the cooling tower tie-in is completed. The Engineering Development Group developed an estimate of the work required to ensure the integrity of the reactor PWS during extended operations, relative to that associated with placing the reactor in a standby mode. The extended operation scenarios under consideration span a range of extended operation times from approximately one to three decades. Reversing the PWS-CWS pressure drop across the heat exchanger, so that tube leakage would not release tritium to the CWS, is also under consideration.

To ensure the PWS integrity during extended operations, a number of tasks that are not planned are recommended and some tasks that are scheduled to end in FY92 should be continued. The tasks are given in the table below.

\begin{tabular}{|c|c|}
\hline TaskNo. & Task Title \\
\hline 1 & $\begin{array}{l}\text { Vibration analysis for extended } \\
\text { charge operation }\end{array}$ \\
\hline 2 & $\begin{array}{l}\text { Revise PWS/CWS structural integrity } \\
\text { analyses }\end{array}$ \\
\hline 3 & $\begin{array}{l}\text { Revise heat exchanger structural } \\
\text { integrity analyses }\end{array}$ \\
\hline 4 & Review group commitments \\
\hline 5 & $\begin{array}{l}\text { In-Tank Component Structural } \\
\text { Integrity evaluation }\end{array}$ \\
\hline 6 & Tank repair technology \\
\hline 7 & Reactor tank inspection support \\
\hline 8 & PWS piping inspection support \\
\hline 9 & $\begin{array}{l}\text { Impact of moderator purity } \\
\text { degradation }\end{array}$ \\
\hline 10 & $\begin{array}{l}\text { Shield system structural integrity } \\
\text { analyses }\end{array}$ \\
\hline 11 & Reactor tank wall irradiation \\
\hline 12 & Reactor tank surveillance program \\
\hline 13 & $\begin{array}{l}\text { Tank supports structural integrity } \\
\text { analyses }\end{array}$ \\
\hline 14 & $\begin{array}{l}\text { PWS and shield support concrete } \\
\text { integrity analyses (required only if } \\
\text { system thermal-hydraulic parameters } \\
\text { are changed. }\end{array}$ \\
\hline
\end{tabular}

These tasks are not tied to a particular operational scenario because they are dependent on the need to ensure system integrity for extended operations. The exceptions are the structural integrity analyses reviews mandated by changes in system thermal-hydraulic parameters associ- 


\section{PROG RESS AND ACCOMPLISHMENTS}

ated with small core operations or the reversal of the pressure drop across the heat exchangers. For example, the effects of potential moderator purity degradation need be considered only if the PWS-CWS pressure differentials is reversed across the heat exchangers.

It is estimated that these tasks would require an additional 3 full time equivalents (FTE) through FY96 beyond that manpower required to support placing the reactor in a standby mode. After FY96, the additional manpower required would drop to 2 FTE. Most of the tasks listed in the table above would be supported under existing programs. Continuation of the tank repair technology development program represents approximately one-half of the additional manpower requirement.

\section{Process Water System Piping Acceptance Criteria \\ D. M. Barnes}

Monitoring of the reactor Process Water System piping through in-service inspection is an important part of the structural integrity demonstration. Replacement Criteria are established defining allowable flaw configurations for piping to remain in service. If a flaw that exceeds the Replacement Criteria is detected, a location-specific evaluation or Acceptance-By-Analysis is required to demonstrate that the final predicted flaw size would not exceed defined safety margins to remain in service. The defined safety margins are adopted from Section XI of the America Society of Mechanical Engineers (ASME) BPV Code, Article IWB-3642 for austenitic stainless steel piping and are $3 \mathrm{X}$ normal operation loads and 1.5X off-normal loads. The methodology was prepared following ASME Section $\mathrm{XI}$ and Nuclear Regulatory Commission Publication 0313 guidance. Flaw stability is determined with a J-integral based Limit Load Method for circumferential flaws and a Limit Load Method for axial flaws. This report also provides recommendations for crack growth rate and weld residual stress models for crack growth analyses.

\section{SRS Full-Scale Pipe Testing Status}

R. L. Sindelar and G. S. Bumgarner

A Savannah River Full-Scale Pipe Testing Program was initiated to maintain a strong position on the continued operability and structural fitness of $\mathrm{K}$ Reactor where future standards or structural models may be required. A technical specification(N-SPP-A-00004) for the Savannah River Full-Scale Pipe Testing Program (see July 1992 MTS monthly report) is in the procurement department. It defines the scope, technical requirements, deliverables, and quality assurance requirements for testing SRS PWS piping at Oak Ridge National Laboratory (ORNL). The SRS testing, to be performed at the ORNL facility constructed for the New Production Reactor-Heavy Water Reactor pipe testing, is tentatively scheduled to begin in March 1993, following the completion of the NPR test program.

The Technology Programs Group, of the Reactor Programs Section of RRD, directed the selection, cutting, and decontamination of degraded (flawed) piping sections from the PWS in 105-C and previously sent one specimen of the piping to ORNL for the NPR pipe test. Two other sections for the SRS pipe test are cut and will be decontaminated by Laboratory Services by the end of August 1992 for shipment to the ORNL facility upon placement of the Memorandum Purchase Order.

\section{K-Reactor Systematic Evaluation Program (SEP): Engineered Safety Features (ESF) Topic Evaluation Plan \\ G. C. Kao, N. K. Gupta and D. M Bames}

The K-Reactor SEP assesses the safety significance of variances between the existing design of $\mathrm{K}$ Reactor's systems, structures, and components and current design requirements, and to perform an integrated assessment of recommended corrective actions that will provide a basis for future plant safety improvements. There are six subtopics defined for the Engineered Safety Features (ESF). Engineering Development Group is supporting the SEP in evaluating three subtopics of the ESF, including the 


\section{PROGRESS AND ACCOMPLISHMENTS}

Emergency Cooling System (ECS), The Water Removal and Storage System and the ESF Materials. The results of the above evaluations were incorporated in the ESF Topical Evaluation Program (TEP), WSRCTR-92-257-005. The TEP was transmitted to DOE for review on July 14, 1992.

\section{K-SAR Amendments \\ R. Boyd}

Amendment 3 of the K-Reactor SAR was completed on July 31, 1992. The amendment consisted of 54 Change Requests (CRs) and over 300 pages of changes. Final review on the amendment print master is ready for submission to Bechtel for printing. After printing is complete, the amendment will be distributed to holders of the SAR. This process is expected to take about a month.

Amendment 4 is in the first stage of review. It should consist of approximately $68 \mathrm{CRs}$ and about 400 pages of changes. The deadline for completion is November 8 , 1992.

\section{SAR Upgrade Program \\ T. Kurt Houghtaling}

Nuclear Safety and Regulatory Analysis received many graphic files from the technical report subcontractor for figures included in CR9100090. WordPerfect 5.1 and Autocad 10 files were modified into SAR figure files for the publication of Amendment 3. Lotus 3.1 files were exported to WordPerfect for modification, and Grapher DXF files were modified via Autocad for publication. Figures that were cut and pasted by the subcontractor were treated similarly.

\section{Computerization of the SARS}

T. Kurt Houghtaling

The computerization of the K-Reactor SAR was summarized and submitted to the editors of the Nuclear Reactor Technology and Scientific Computations newsletter.

A program plan for general computerization of documents was formulated. Cost estimates to a prospective customer depend greatly on the complexity of the document and what type of user interface the customer might want. A rough estimate for establishing a text-only database is $\mathbf{8 0}$ man-days. Inclusion of graphics is possible, but will not be of value to users until the SRS computer infrastructure is upgraded. Even then, graphics or images may be problematic until additional hardware and software can be integrated.

\section{Pipeflow (K-Reactor ECS/CWS Model) G. A. Bevirt}

The technical task plan SRT-STR-92-8004, The Conversion of NES PIPEFLOW Version 1.0 Model to the Format for PIPEFLOW Version 3.0 (U) received the required approvals. L\&SA converted the three NES models and the new models are producing CWS flows identical to the earlier version of the code. Two models showed ECS flowrate variations that are related to operation near the ECS "cutoff head". The valve arrangements in these two models are not normally associated with plant operations of accidents. NES will be providing two different valve alignments for the models that will produce realistic and comparable ECS results.

The following steps were taken to update the NES PIPEFLOW 1.0 models to PIPEFLOW 3.0:

- converted NES model input files

- added NPSH data to the pump parameters

- aligned Tee and Wye losses between the models

- executed PIPEFLOW version 3.0 with the updated input files and evaluated hydraulic anomalies

- compared the updated model results with those from PIPEFLOW version 1.0

\section{Technical Specification Change Requests (TSCR)}

\section{J.S. Lietzow}

TSCR 92-0008 - Incorporation of the Plant Operating Specifications and development of Bases into the Technical Specifications continues (C.Smith). 


\section{PROGRESS AND ACCOMPLISHMENTS}

TSCR 92-0013 - A new TSCR was issued to remove an existing Technical Specifications (TS) interpretation to TS 3.2.1 (Full Length Control Rod Positioning). It addresses flux control below the Instrument Shape Applicability Limit (B. Ingerto).

TSCR 92-0014-Replacement of the existing Electrical Technical Specifications in their entirety with new TSs based on the Westinghouse Standard TS (Methodically Engineered Restructured Improved Technical Specifications) format continues. TSCR 92-0012 (TS 3.8.3.2, Emergency GM Diesel) will be incorporated into this TSCR (M. Layton).

\section{Cooling Water Basin Level Instrumentation \\ E.Y. Hwang}

Channel uncertainties, relating to the new Cooling Water Basin Level Instrument circuits, are being evaluated in support of the Cooling Tower Task Team efforts. The existing level instrument uncertainties are also being evaluated to obtain performance improvement. Work is continuing in cooperation with Reactor Engineering, the Power Department, and the Engineering and Project Division personnel to collect and examine the relevant engineering specifications, DPSOLs (DuPont Standard Operating Log), Work Instructions, vendor literature, and drawings on operation and calibration procedures for the basin level instruments. The uncertainties for each element in the circuit are being evaluated and an engineering evaluation report is being prepared.

\section{Leak Testing Replacement Heat Exchangers for $\mathrm{K}$ Reactor}

\section{J. Trapp, H. B. Hoover, J. H. Ouzts, T. L. Usry, and R. L. Yongue}

The reactor department requested that EES perform a helium leak test on ten heat exchangers as part of a program to replace ten of the twelve K-Reactor heat exchangers. To date, EES tested eight of the heat exchangers. Two units from L Reactor remain to be dried and leak tested. Three of the units that were tested were installed in $K$ Reactor. Reactor Operations will replace the remaining heat ex- changers this fall during the K-Reactor outage for the tie-in of the new cooling tower. Reactor Maintenance recently turned over support responsibilities to Construction which will allow Maintenance to perform other K-Reactor shutdown tasks.

Heat exchanger L5B was successfully vacuum dried and leak tested. It was moved out of C-Stack and L3B was moved in. Construction is preparing it for vacuum drying and leak testing.

Two new vacuum pump skids, which were custom made for SRS by Kinney Vacuum, were started and tested with assistance from the vendor. These skids will be used to vacuum dry L-Reactor heat exchangers when construction prepares them for long term storage.

\section{Effluent Water Assimilation Monitor}

\section{R. F. Eakle, Jr. and G. E. Reeves}

EES provided assistance to the Environmental Technology Section (ETS) of SRTC in the expedited installation of a tritium effluent water monitor (TEWM), formerly called effluent water assimilation monitor, for $\mathrm{K}$ Area following an accidental release of tritium in early 1992. As a follow up, EES is developing improved instrumentation to support ETS monitoring technology. The instrumentation will provide improved time response and reliability in tritium detection. These improvements will be achieved by integration of electronics and efficient fluid handling packaging systems. A miniature flat panel display computer will monitor and control system functions including diagnostics. The hydraulic portion of the system will incorporate particle filtration, organic removal, ultraviolet sterilization, and ion exchange. The resulting ultra-pure water should extend detector life and reduce the possibility of clogging due to chemical impurities. A sensor monitors pressure at four stages of the filtration process and provides information to the computer which will determine if maintenance is required. The hydraulic and electronic portions of the new TEWM are modular and compact so the system can be installed in a confined area.

The assembled TEWM was operational at $L$ Area Lake on August 3, 1992 and operates as a scoping activity prior to final installation in Building 614-2K. Operation at L Area Lake will allow for adjustments and development 
of procedures and will help establish maintenance frequency. The expected $\mathrm{K}$ Area installation date is September 30, 1992.

\section{Manual Control Module Upgrade (MCM) - Control Rod Drive System, 105-K}

T. R. Talarek

The MCM allows reactor operators to access T-amplifier signals and manually position the control rods. The existing MCM does not have the capability to move the control rods at slow speeds or to determine rod position information with sufficient accuracy. RE requested that Equipment Engineering build a prototype MCM with these features and several other upgrades.

\section{Area Heavy Mark 16B Storage Limits \\ J. F. Mincey and J. F. Zino}

Heavy Mark $16 \mathrm{Bs}$, discovered in 1985 , unintentionally exceeded existing Mark 16B Technical Specifications on U-235 linear density limits. A 1986100 Area study estimated the reactivity worth of the higher U-235 loading and argued it was negated by the increased U-236 loading. A series of test authorizations were subsequently used to approve storage of these heavy Mark 16Bs until a permanent change to the Technical Specifications was sought. DOE DP-62 challenged whether or not an independent technical review of the original reactivity study was done and decided to have LANL conduct an independent review. LANLs calculations confirmed the validity of storage limits but led to challenges of the computational methods used at WSRC for the 1986 evaluation. Further discussions are in progress to resolve these concerns. 


\section{PROGRESS AND ACCOMPLISHMENTS}

\section{TRIIIUM}

\section{Task Team to Reduce Tritium Losses}

\section{A. Fisher}

A task team was formed to identify areas in tritium facilities that contribute to tritium loss. Their purpose is to propose and implement methods that would reduce these tritium losses. The task team includes representatives from Tritium Technology, Tritium Operations, Tritium WE, $\mathrm{HP}$, and Hydrogen Technology.

Hydrogen Technology could contribute to the task team's efforts in several areas. One area is the off-gassing of cut reservoirs and decommissioned equipment. Offgassing from these materials accounts for a significant quantity of routine tritium loss from the tritium facilities (five percent based on previous estimates).

Tritium removal from these off-gassing streams can be accomplished by using the catalytic exchange stripper technology for deuterium and tritium removal from $\mathrm{He}$, N2, and air streams, demonstrated by L. K. Heung, G.W. Gibson and M. S. Ortman. Decontamination factors as high as 1,000 were reported, depending on the inlet tritium or deuterium concentration and the type of gas streams. Regenerating the stripper can also recover the removed tritium in elemental form.

Another potential application of a catalytic exchange stripper is the tritium removal of waste oil off-gas streams. However, these gas streams contain tritiated organic species and elemental tritium and tritium oxide. Therefore, the performance of the stripper in the presence of gaseous organic species would require investigation. These exchange stripper applications will be discussed at upcoming task team meetings.

\section{RTF Process Cooling Water Contamination}

\section{J. E. Klein and M. L. Moore}

Contamination rates were estimated for the RTF Process Cooling Water System (PCWS). Tritium permea- tion into the PCWS comes from permeation from the glovebox atmosphere into the cooling lines exposed in the gloveboxes, permeation from process vessel lines into cooling lines soldered to these lines, permeation from the glovebox stripper system into the Stripper Coolers, permeation from the U-bed process lines into the U-bed Cooler PCWS flows, and permeation from the glovebox atmosphere into the PCWS through glovebox heat exchangers.

Conservative estimates give a contamination rate of $15 \mathrm{mCi} / \mathrm{yr}$ after four years of operation and will have minimal impact on RTF operations. This permeation rate is equivalent to a leak rate of $1.8 \times 10^{-13} \mathrm{cc}-\mathrm{atm} / \mathrm{sec}$, which is over $\mathbf{1 0 0 0}$ times smaller than the typical leak rate on a bellow seal valve. At this rate it will take over five years of RTF operation to reach the Environmental Protection Agencys (EPA) safe drinking water limit of $20 \mathrm{pci} / \mathrm{ml}$. The report (WSRC-TR-92-356) describing the details of the PCWS contamination estimates will be issued.

\section{Technical Review of the RTF Final Safety Analysis Report (FSAR)}

T. Motyka, A. S. Horen, J. E. Klein, I. A. Fisher, and J. H. Owen

HTS personnel provided a detailed review of Chapters $1,2,4,5,6,7,9,11$, and 14 of the RTF FSAR and the responses to comments generated by previous reviews. WSRCs approval of the RTF FSAR is an award-fee milestone.

Several items were highlighted during this review. They include:

- Information pertaining to organizations, their responsibilities, and project commitment dates, should be updated (All chapters).

- Items referencing Loading Lines 1 \& 6 should be removed to reflect current project scope (All chapters).

- The stripper system will operate at 10,000 ppm oxygen (All chapters).

- TCAP operational information should be changed to reflect current operating philosophies (Ch. 6).

- Hydride bed and other packed bed disposal should be discussed more thoroughly (Ch. 14). 
- The decontamination factor, used to determine stripper system operability (primary, secondary, and purge), should be better defined (Ch. 9, 11).

These comments, and other minor editorial comments that were generated during the review process were forwarded to M. L. Moore (NPSR) for consideration and incorporation into the approval copy of the RTF FSAR.

\section{Hot and Cold Nitrogen Issues Task Team}

\section{A. S. Horen and F. B. Ramirez}

HTS participated on the RTF Hot and Cold Nitrogen issues task team that addressed condensation and insulation concerns. Two primary issues were addressed during the meetings: condensation dripping from the cold nitrogen lines in the process rooms (TCAP/Diffuser and P-Evac) and water formation outside of the gloves on the TCAP glovebox.

The first issue was addressed by RTF Projects, Design Engineering and Construction. Additional insulation is being installed on these lines to bring the insulation to design specifications.

On the TCAP glovebox, water condensed outside of the gloves during testing when many of the hydride beds were in the "Full Cool" mode. During the tests, the glovebox temperature was about $55^{\circ} \mathrm{F}$. The "worst case" room environment design conditions $\left(76^{\circ} \mathrm{F}, 60\right.$ percent relative humidity) gives a dewpoint of $61^{\circ} \mathrm{F}$. Actual conditions in the process rooms were about $70^{\circ} \mathrm{F}$ and 80 to 85 percent relative humidity (dewpoint $60-65^{\circ} \mathrm{F}$ ). Root causes for the water formation include low glovebox temperature, due to inadequate insulation on the hot/cold nitrogen lines (common) in the glovebox and lack of humidity control in the process rooms.

Additional insulation will be designed and installed in the TCAP glovebox to increase the insulation surface temperature above the dewpoint at designed environment conditions. Also, the building temperature/humidity parameters will be adjusted to meet design specifications. Two alternative solutions were to add heat to the glovebox to bring its temperature above the dewpoint and to provide spot environmental control (temperature, humidity) in the process room(s). HTS will investigate the possibility of defining the temperature/pressure of the hydride storage beds such that they are not in the "FULL COOL" mode for extended periods of time.

\section{Reserve Kieselguhr for the Replacement Tritium Facility W. C. Mosley}

Kieselguhr, in the form of $30-40$ mesh granules of calcine and acid-washed diatomite, is used in the Plug Flow Reversers (PFR's) in TCAP units in the RTF.

The material in the PFR was a Level 1 procurement item purchased in 1988 as $30-40$ mesh Chromosorb P(AW) from Manville Sales Corporation. Level 1 designation was required because the standard Chromosorb $\mathrm{P}(\mathrm{AW})$ product was 30-60 mesh and sieving was required to produce a 30-40 mesh material. In March 1991, RTF requested that HTS procure additional kieselguhr as reserve material for the RTF.

A 1990 Level 1 procurement of 30-40 mesh Chromosorb P(AW) for a TCAP PFR failed because of personnel changes at Manville and their decision to sell through a distributor rather than directly to customers. The distributor, SouthChem, Inc. of New Bern, NC, agreed to sell 30-40 mesh Chromosorb P(AW) as a standard item (PAW 30/40, catalog \#2558). Therefore, the reserve RTF kieselguhr was ordered from SouthChem as a Level 2 procurement item in August 1991. The purchase order specified that samples be sent to WSRC for analyses to confirm that chlorine content did not exceed the $250 \mathrm{ppm}$ maximum before the material was accepted and shipped, as required by Site Specification No. 5992. Delivery of the samples was delayed because Manville sold their diatomite business to the Celite Corporation and WSRC Receiving returned the first shipment of samples because of incomplete marking. The samples were finally received in May 1992 and neutron activation analysis detected no chlorine (detection level was about $50 \mathrm{ppm}$ ) in Chromosorb P(AW) Lot $\mathbf{5 2 3}$ designated for this order. Shipping approval was given and the material was received at SRS in July 1992.

After receipt at SRS, the reserve RTF Chromosorb $\mathrm{P}(\mathrm{AW})$ was analyzed for particle size distribution and chlorine content. Sonic sieve analyses of three random samples from Lot 523 showed $91.1,90.2$ and 90.0 percent 


\section{PROGRESSANDACCOMPLISHMENTS}

in 30-40 mesh. The specification developed for Level 1 procurement required that at least 90 percent of the particles be in the 30-40 mesh range. Neutron activation analysis detected no chlorine in the three samples. Thus, the reserve RTF kieselguhr meets established specifications and is acceptable for RTF usage. SRTC HTS is storing the material until needed by the RTF.

\section{Activity Transfer Group Meetings (K. A. Dunn, K. M. Keeler)}

Formation of Activity Transfer Groups (ATG) was the result of the Non-nuclear Consolidation Plan (NCP) to downsize the DOE Nuclear Weapons Complex. The purposes of the group are to provide the structure, objectives, and deliverables necessary for the transfer of operations from donor sites to receiver sites. Component Evaluation Operations (CEO) and Gas Transfer Systems (GTS) of EG\&G Mound Laboratories are scheduled to be transferred to SRS as part of the NCP. CEO and GTS ATG meetings outlined schedules for the transfer of equipment and technology and to provide a Comprehensive Implementation Plan for the activities. These implementation plans address items such as assumptions, issues and concerns, scheduling, qualification plans from the design agencies, Environmental Protection, Safety, and Health (EPS\&H) concerns with the workload, and critical skills for transfer from Mound Laboratories to SRS. Input from ATG members is addressed in the implementation plan. Specific items of concern is within each implementation plan, shown below.

\section{Gas Transfer Systems (GTS)}

The implementation plan assumes that "Special Units" will be processed at Mound Laboratories prior to the September 1995 cessation date and "Special-units" will be transferred to Los Alamos National Laboratory (LANL). In addition, it assumes that there are sufficient shipping containers available to ship storage units to SRS. The environmental units are scheduled to be shipped from June 1994 to September 1995. The remaining ambient temperature units will be packed in shipping containers by September 1995 and shipped between September 1995 and September 1996.
Issues and Concerns include Mound Laboratories' position that they cannot unload Vineyard units and that they may not be able to unload all scrapped development units by the September 1995 cessation date.

Because of the scheduled 1.5 years between Mound Laboratories' shutdown and SRSs startup, several issues were identified. They include loss of data from the environmental units during ambient temperature storage and shipping, a lack of monitoring facilities at SRS for reservoirs that are received from Mound prior to the September 1997 startup, and the inability to perform cross correlation tests between the GTS function testers at Mound Laboratories during startup at SRS.

\section{Component Evaluation Operations (CEO)}

The implementation plan assumes that pneumatic burst testing will be required at SRS and hydrostatic burst testing of reservoirs will not be required. A position paper concerning pneumatic burst testing at SRS, SRTHTS-92-0084, was reviewed and discussed by ATG members. The plan also assumes that the Design Agencies and Mound personnel will provide technical support for design of CEO facilities.

LANL provided a qualification plan for CEO equipment in letter WX-5-92-0583-U for incorporation into the implementation plan. This letter outlined the test requirements for the function testers and the burst tester. Sandia National Laboratory-Livermore (SNLL) will provide the required qualification plan for inclusion in the implementation plan.

According to the Design Agencies, a thirty month hiatus between Mound Laboratories' scheduled stop date for CEO work, March 1995, and SRS's startup date, September 1997, will put the surveillance testing at serious risk with regard to stockpile safety and reliability. Because of the hiatus, the reservoirs at the end of their Limited Life Component Evaluation cycle will go past their scheduled surveillance check by 24 months. In addition, the testers (vibration, drop, centrifuge, and burst) at Mound Laboratory will not be available to perform cross correlation tests with WSRC testers to ensure continuity of data. 


\section{PROGRESS AND ACCOMPLISHMENTS A}

\section{Surface Defect Detection Algorithms for True Color Tube Bore Inspection System (TCTBIS) \\ M. J. Pechersky and R. K. Dickerson}

Reservoir fill stem bore quality is essential to the integrity of the subsequent pinch welds done on the stem. The degree of oxidation of the stem is inversely related to the quality of the pinch weld. Also, the presence of foreign matter, scratches on the inside of the stem, and other abnormalities such as excessive etching or blotching, could decrease the integrity of the pinch weld.

Previous work demonstrates that the TCTBIS can characterize surface quality of the bores of reservoir fill stems. Not only can the degree of oxidation of the stem be evaluated nondestructively with this system, but scratches would also be detected. The work described refines the capabilities of the TCTBIS to objectively characterize the surface of fill stem bores with regard to surface imperfections and by further analyzing data from images collected by the TCTBIS in the earlier study. Several methods of processing were used to discover an objective method by which the surface quality of the bores may be graded for nondestructive evaluation purposes in a way that does not require extensive visual interpretation of the unwrapped images.

Several processing algorithms, which include low pass filtering and image binarization, were applied to the TCTBIS images with a limited degree of success. Due to its limited capabilities, the CUE-2 image analyzer system severely restricted the processing that could have been accomplished. Therefore, after processing, the current data were discovered to be extremely noisy, making the numeric detection of abnormalities within the bore difficult. While the processed images clearly showed the presence of the defects, additional work remains to develop an algorithmic interpretation of the image data. A new image processor, with enhanced processing capability, was ordered to obtain improved results. This image processor is a single expansion card with greater speed and versatility than the CUE-2 system and will be installed in the TCTBIS computer. The CUE-2 system is a stand-alone system that acquired the images from the TCTBIS monitor. This cumbersome step will be eliminated when the new image processor card is installed.

\section{JBF Test Program \\ W. J. Rogier}

In response to SNLLs request, the JBF program kickoff meeting was held on August 13, 1992 with representatives of SNLL, the Hydrogen Technology Section, the Tritium Technology and Engineering, the Tritium Operations Department, the Equipment Engineering Section, the Materials Technology Section, and Environmental, Safety, Health and Quality Assurance. The following topics were discussed in detail:

- The program consists of three sets of 17 units. Mound Laboratories loaded the first set with Tritium and put it in storage. Two units will function at Mound Labora. tories and the remaining 15 need to be shipped to SRS for further testing. An additional set of units, that were not loaded, is also located at Mound Laboratories. Details on shipment of the loaded and unloaded units were discussed.

- Unit configuration was studied in great detail. Because of possible safety concerns, a recommendation to add a valve to all units was agreed upon. In addition, loading methods and loading locations were evaluated. The possibility of loading these units in the RTF was discussed and will require further consideration.

- The different storage conditions of the testing program were discussed. Storage in secondaries, varying storage temperatures, and typical storage lifetimes were reviewed.

A probable breakdown of responsibilities among SRS personnel, which would be quite similar to the current assignments in the HP-Block program was discovered. To prepare for future activities, SNLL agreed to send sample hardware. This will aid in the planning of calorimetry technique and secondary configuration. The next coordination meeting with SNLL personnel will be held in mid to late October 1992.

\section{Tritium Consolidation} Implementation Plan for Commercial Sales/ICF Loading

W. N. Posey

The most important portions of the implementation plan for Commercial Sales and Inertial Confinement 


\section{PR OGRESS AND ACCOMPLISH MENTS}

Fusion (ICF) Microsphere Loadings, was drafted for submission to DOE Albuquerque, NM. It reads:

\section{Executive Summary}

All DOE Tritium and Helium-3 Commercial Sales operations and all ICF Target loadings are currently performed by Mound Lab. DOE's proposed Non nuclear Consolidation Plan will transfer all tritium loadings for Commercial Sales/Inertial Confinement Fusion (ICF) microspheres to SRS. Mound currently loads -70 containers/yr with $\mathrm{T}_{2}$ at $\leq 1 \mathrm{~atm}$ pressure and room temperature. An additional 12 batches/yr of ICF microspheres are loaded with HDT mixture at $\leq \mathbf{1 0 , 0 0 0}$ psi and $\leq$ $400^{\circ} \mathrm{C}$. DOE's income from the sale of $-500,000$ curies $\mathrm{T}_{2} / \mathrm{yr}$ is $\sim \$ 1,600,000$. This project's objective is to establish facilities and technologies at SRS to accurately load, package, and ship the $T_{2}$ loaded containers to commercial customers, federal agencies, and other DOE facilities.

A third sales operation done at Mound, that may be transferred to SRS is the ${ }^{3} \mathrm{He}$ purification/sales, which was not addressed in SRS's Conceptual Design Report for Tritium Consolidation. Therefore, an additional objective of Commercial Sales is to establish ${ }^{3} \mathrm{He}$ purification facilities at SRS, if directed by DOE.

\section{Production Capability}

The SRS RTF inert atmosphere gloveboxes, where loading of the units is planned, has sufficient loading capacity to exceed the number of $\mathrm{T}_{2}$ commercial sales and ICF units currently loaded by Mound.

\section{Assumptions}

Tentative Loading/Sales Schedule Support - $\mathrm{T}_{2}$ commercial sales and ICF customer loading schedule requirements will be met as follows:

- Small SS cylinders can be loaded in the RTF's Mass Spec. Glovebox after January 1995.

- U-beds can be loaded in the product container loading facility in Building 232-H after March 1995. Upon completion of the appropriate RTF Loading Line, Ubeds will be loaded.
- ICF microspheres can be loaded in the appropriate RTF Loading Line after June 1995. Upon completion of the appropriate RTF Loading Line, ICF targets will be loaded.

- $\mathrm{He}_{3}$ Purification for Commercial Sales can be available from SRS by January 1996, if directed by DOE.

\section{Equipment Transfer Planning}

- The commercial sales equipment planned for transfer to SRS consists of Mound's supply of small 316L SS gas containers, the DOT-7A Type A shipping containers for the gas containers, the U-beds, and the DOT Type B shipping containers for the U-beds.

- No equipment for the ICF loadings and shipping are planned for transfer to SRS.

- No equipment from the ${ }^{3} \mathrm{He}$ purification process will be transferred to SRS.

\section{LANA 0.75 Tritium Isotherms after 5 Years of Exposure}

J. R. Wermer, D. E. Moseley, and M. L. Johnson

A tritium desorption isotherm, after 1799 days of exposure, was determined for the LANA75T5 sample, which is $\mathrm{LaNi}_{4.25} \mathrm{Al}_{0.75}$ (LANA 0.75). This isotherm showed increased slope and decreased reversible capacity compared to the previous isotherm determined after 1423 days. The isotherm was determined at $80^{\circ} \mathrm{C}$. During the determination, the sample was heated to $150^{\circ} \mathrm{C}$ after the desorption pressure dropped to $<10$ torr, producing a second isotherm. The $150^{\circ} \mathrm{C}$ isotherm gives the determination of the tritium "heel", which is defined as the amount of tritium that could not be easily removed from the sample at a temperature of $150-160^{\circ} \mathrm{C}$. The tritium heel increased to $\mathrm{T} / \mathrm{M}=0.146$ after 1799 days. The previous determination after 1423 days showed a heel of $\mathrm{T} / \mathrm{M}=0.119$.

\section{Thermal Cycling of Heat Treated RTF $\mathbf{P d} / \mathbf{k}$}

I. A. Fisher, S.V. Parks and L. E. Vines

$\mathrm{Pd} / \mathrm{k}$ was heat treated for approximately two hours at $1100^{\circ} \mathrm{C}$ in air to increase the resistance to mechanically induced decrepitation and decrepitation due to thermal 
cycling. A sample of the heat treated $\mathrm{Pd} / \mathrm{k}$ was thermally cycled for 4,500 cycles in protium between $-40^{\circ} \mathrm{C}$ and $150^{\circ} \mathrm{C}$. After cycling, the particle size distribution was measured by the Analytical Development Section (ADS).

Thermal cycling of $\mathrm{Pd} / \mathrm{k}$, which received no heat treatment, was performed under the same conditions as the heat treated $\mathrm{Pd} / \mathrm{k}$. Nine thousand cycles accumulated and the results showed that a stable particle size distribution was obtained after 4,000 cycles. Moreover, the 4,000 cycles resulted in a 40 percent reduction $(327 \mu \mathrm{m}$ to 196 $\mu \mathrm{m}$ ) in the weight averaged particle size compared to the uncycled sample.

The heat treated $\mathrm{Pd} / \mathrm{k}$ was cycled 4,500 times. ADS measured the percentage distribution using the same method that was used to measure the particle size distribution of the non-heat treated $\mathrm{Pd} / \mathrm{k}$. The 4,500 cycles resulted in an 18 percent reduction $(384.5 \mu \mathrm{m}$ to $315 \mu \mathrm{m})$ in the weight averaged particle size compared to the uncycled sample. This reduction in particle size is substantially less than that for the non-heat treated $\mathrm{Pd} / \mathrm{k}$, indicating that the heat treatment significantly improves the resistance of the $\mathrm{Pd} / \mathrm{k}$ to particle decrepitation resulting from thermal absorption/desorption cycling.

The particle size distributions for the uncycled and cycled non-heat treated $\mathrm{Pd} / \mathrm{k}$ and the distributions for the uncycled and cycled heat treated $\mathrm{Pd} / \mathrm{k}$ are shown in the figure below. The figure clearly shows that the cycling of the heat treated $\mathrm{Pd} / \mathrm{k}$ results in the generation of miminal quantities of smaller particles, compared to the non-heat treated $\mathbf{P d} / \mathbf{k}$.

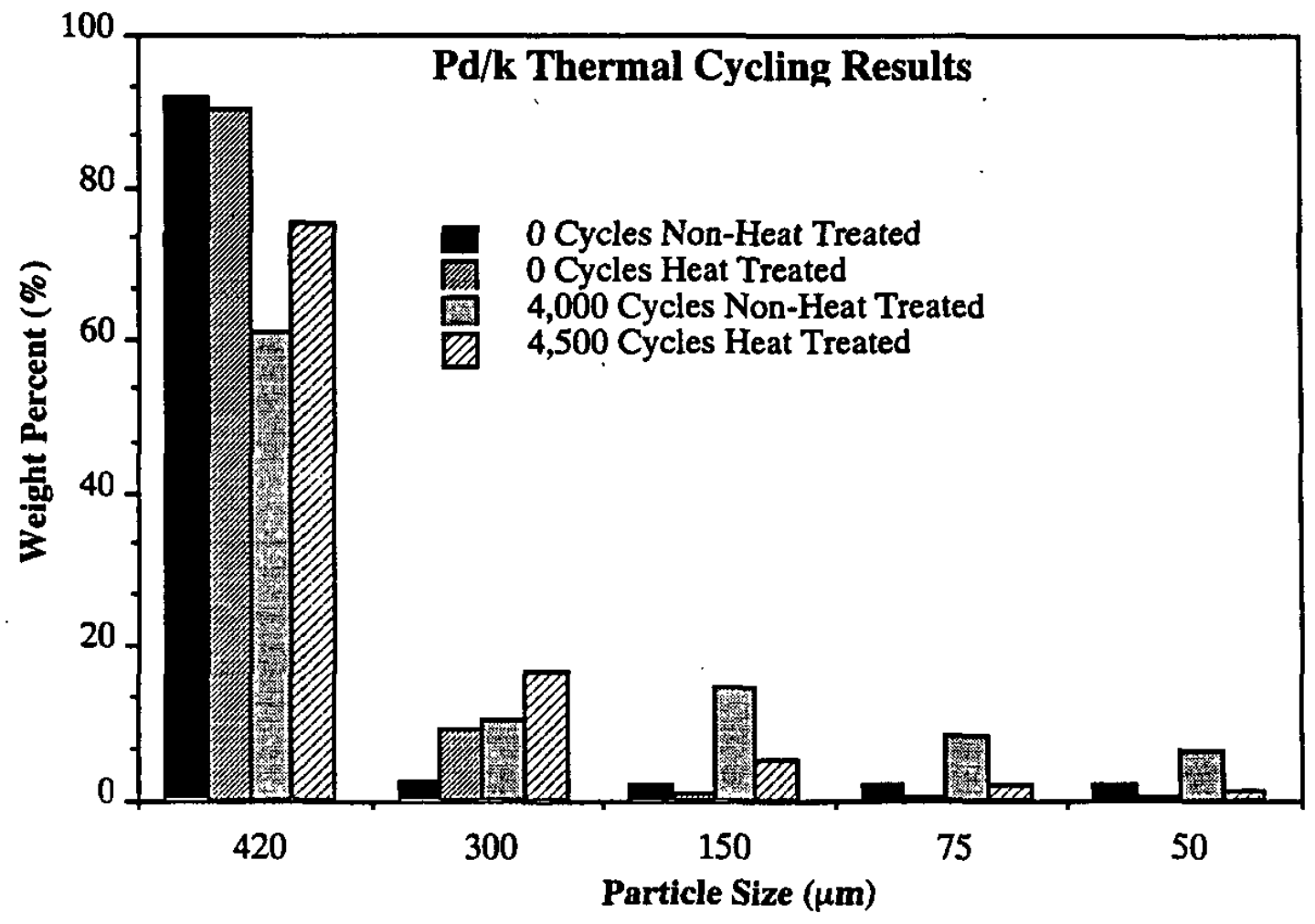




\section{PROGRESS AND ACCOMPLISHMENTS}

\section{"Improved" Pd/k Characterization via Desorption Isotherms}

\section{J. S. Hol̈der and W. L. Moyer}

The palladium supported on kieselguhr $(\mathrm{Pd} / \mathrm{k})$, to be used in several applications in the RTF, is produced by repeated deposition from a palladium chloride solution. Materials in contact with stainless steel in production facilities at SRS may not contain more than $250 \mathrm{ppm}$ chlorine, which necessitates special care to remove chlorine from the $\mathrm{Pd} / \mathrm{k}$. To alleviate this problem, "improved" $\mathrm{Pd} / \mathrm{k}$ is produced from a palladium ammonium solution.
The "improved" $\mathrm{Pd} / \mathrm{k}$ was subjected to a series of hydrogen and deuterium desorption isotherms at $30^{\circ} \mathrm{C}$, $80^{\circ} \mathrm{C}$, and $130^{\circ} \mathrm{C}$. The results of those measurements are shown in the accompanying semi-log plot of equilibrium pressure versus composition (the atomic ratio of $H$ or $D$ to Pd). A hydrogen absorption isotherm at $30^{\circ} \mathrm{C}$ (not shown) was also collected prior to transferring the hydride bed and material to the MTF for tritium measurements. These data are being analyzed and compared to RTF $\mathrm{Pd} / \mathrm{k}$ and palladium powder isotherms to determine if the new processing method affects more than the chlorine content of the material.

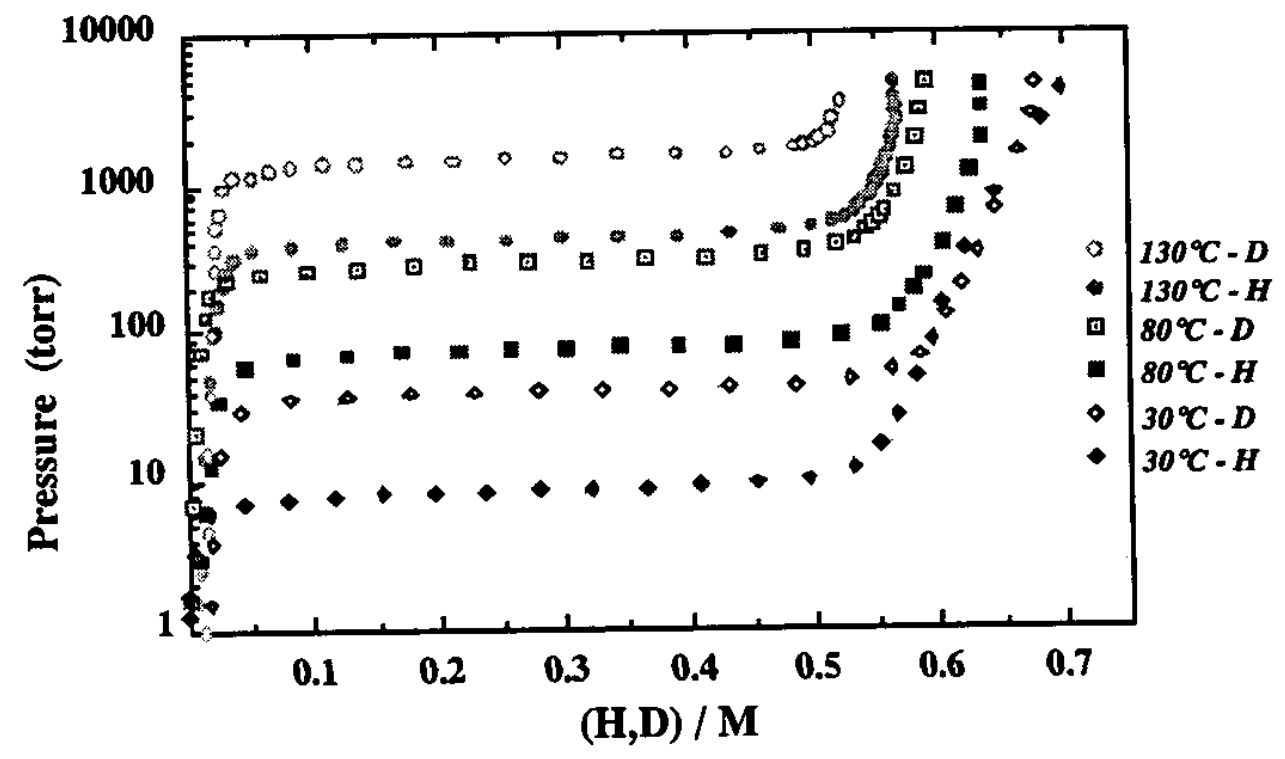




\section{PROGRESS AND C COMPLISHMENTS}

\section{Life Storage Program}

H. D. Brown

The Life Storage Program is an on-going stockpile surveillance program designed to assure reservoir reliability. This involves loading, unloading, reclamation, and destructive testing of reservoirs.

Tritium Operations is planning to begin unloading 25 Special reservoirs by the end of the month.
Permeations by Ion-Current Measurement (I/C/M) is running on a monthly basis. One hundred percent of the scheduled I/C/Ms ran this month.

One reservoir was unloaded for SRTC this month. No reclamations or refills were done.

The Burst test facility is not functioning.

Controllers for the new environmental chambers should be installed within the next month. 


\section{PROGRESS AND A CCOMPLISHMENTS}

\section{SEPARATIONS}

\section{Americium-Curium Solution}

\section{J. H. Gray and R. W. Wainwright}

The ability to poison an americium-curium (Am-Cm) solution with gadolinium (Gd) or uranium (U) shows promise. Simulated Am-Cm solutions containing the $\mathrm{Gd}$ and $U$ poisons were stored for one month. The $G d$ and $U$ remained with the solids. The neodymium substitute for curium also remained in the solid phase.

A plan is being developed for sampling tank 17.1 and testing the actual Am-Cm solution in SRTC under longterm storage conditions.

\section{FB-Line JCO}

P. L. Fisk

The revised JCO was transmitted to Nuclear Materials Planning Division (NMPD) on July 24, 1992 and transmitted to DOE-SR on July 29, 1992. Revisions included incorporation of various comments and a more thorough bounding accident analysis. Source terms for the bounding accidents in the JCO were conservatively based on Nuclear Criticality Safety Supplements, versus the nominal batch sizes used in the SAR.

\section{Ruthenium Volatilization in FB-Line Processes}

\section{E. A. Kyser}

An Operation Safety Requirement (OSR) verification effort questioned FB-Line compliance with the offgas OSR regarding ruthenium volatilization. The drying/roasting steps and dissolution of slag and crucible in recovery are the only process steps in FB Line that have the potential for ruthenium volatilization to occur. An analysis of the chemistry of Ru in the FB-Line processes was performed. It indicated that less than $0.04 \mathrm{mCi} /$ year of ${ }^{106} \mathrm{Ru}$ is expected to be released to the sand filter by FB-Line operations. Procedural changes are not warranted to ensure OSR compliance on this issue.

\section{Checkout of FB Line OLAM}

\author{
R. A. Dewberry
}

Several years ago, the Analytical Development Section (ADS) installed an on-line alpha monitor (OLAM) on the cation waste stream to canyon tank 9.7. Because this tank is not geometrically favorable for criticality concerns, proper operation of the OLAM is important for FB-Line restart. Recently, in a joint effort of ADS and B-Line personnel, the OLAM was restarted after an extended outage. The instrument appeared to be in good operating condition, however, the count rate was greater than expected. This probably indicates a buildup of activity on the scintillator. Acid flushes will reduce the background counts.

\section{FB-Line 9968 Procurement Effort G. A. Lucky, G. Cadelli}

Fabrication drawings of the 9968 package were sent to Lawrence Livermore National Laboratory (LLNL) for procurement bid purposes. Although DOE/HQ did not officially approve of the drawings, the design is representative and adequate for procurement bidding. Inquiries on possible 9968 procurement were also received from Los Alamos National Laboratory (LANL) and were referred to DOE-SR for resolution.

\section{High Pu Content Waste Pails Measured For 235-F \\ R. A. Dewberry}

SRTC-ADS-92-0284 was issued. It gave the recalculated values for the Pu-239 content of four 235-F waste pails that contained Rocky Flats ash originally transferred to SRS for recovery. Attempts to assay the pails with the normal 235-F waste pail monitor were suspect because the monitor was designed for gram quantities of $\mathrm{Pu}$. The recalculated values were based on measurements using a far-field passive gamma-PHA configuration that doubled the precision. 


\section{PROGRESS ANDACCOMPLISHMENTS}

\section{1-H Canyon SAR Update}

J. M. Low and N. M. Hassan

The consequence analysis in the 221-H Canyon SAR is being updated from ICRP-2 to ICRP-30 methodology. In the $S A R$, doses are calculated for the maximally exposed offsite individual, the offsite population, and the onsite population. Accident consequences to these groups increased by factors of $4.7,2.5$, and 6 , respectively. The work was completed and documented in a Calc-Note. SAR page changes will reflect the new consequence and risk values.

Because of increased interest in accident consequences to onsite personnel, Nuclear Processes Safety Research (NPSR) is also calculating doses to the facility operator at the site of the accident, personnel in the adjacent areas in the facility, maximally exposed individuals in the area (excluding the initiating facility), and area population (excluding the initiating facility).

\section{1-H Outside Facilities SAR}

J. M. Low

The Analysis and Justification Report (AJR) to support the OSRs for the Uranyl Nitrate Storage Tank was reviewed by Separations, Separation Technology, and NPSR personnel. The AJR documents the thought process and the design basis used to develop the OSRs.

DOE-SR provided additional comments on the 211- $H$ SAR. Several comments arose, three regarding updated fire protection information from the DOE Industrial Safety Branch and five regarding consequence analysis from the DOE Radiation Protection Branch. These comments are not thought to be significant. NPSR is preparing responses for incorporation into the 211-H SAR.

DOE-SR provided six minor comments on the UN Tank Compliance Review. NPSR is preparing responses to these comments.

\section{H-Canyon Sand Filter}

J. H. Gray and R. W. Wainwright

A dark brown, oily, damp material from the top layer of an H-Canyon sand filter was sent to SRTC for analysis.
Concern was expressed that an organic component may have collected in the sand filter.

As expected, the sample was primarily silica. The dark brown, oily appearance was attributed to hydrated iron oxide, a gelatinous, red-brown, amorphous material. No organic material was present. A trace amount of cesium-137 was found, but no chromium or nickel. This iron oxide probably came from the corrosion of mild carbon steel rather than stainless steel.

\section{Solids in H-Canyon Tank 7-3.1 E. A. Kyser}

The Chemical Technology Section assistance was requested to aid in the identification of solids that were found in accountability samples from the Pu-238 heel in tank 7-3.1. Due to the heat generated by its Pu-238 content, the heel loses volume from evaporation relatively quickly and requires periodic dilution. Because this tank contains non-fissile Pu-238 and there is a desire to keep the acid concentration down prior to transfer to $\mathrm{HB}$ Line, water was added routinely without incident. Over the last five months, water was added every four to six weeks, as necessary. After the most recent dilution, accountability samples from the tank contained green solids and the solutions were pale green rather than the normal brown. Acidity of the sample was much lower than expected.

A quick review of literature revealed that under these conditions alpha radiolysis of nitric acid becomes significant at nitrate concentrations above one molar. At the lowest volumes, this heel solution should have been 6 to 7 $\mathrm{M} \mathrm{HNO}_{3}$, which would have resulted in an acid consumption rate of eight percent per week rather that the two percent per week that occurs at normal acidities. After repeated cycles, the acid would be depleted to the point that polymerization would occur during water addition.

H-Canyon personnel are aware of this mechanism for loss of acid from stored Pu-238 solutions. This problem is not seen with Pu-239 solutions because of lower specific activity. It appears that no other $\mathrm{Pu}-238$ tanks should have a significant acid depletion problem because this was the only tank where $\mathrm{Pu}-238$ was being stored in low acid at multigram/liter Pu-238 concentrations. The acid content of this tank was raised to prevent additional polymer 


\section{PROGRESS AND ACCOMPLISHMENTS}

formation and plans are being prepared to transfer the solution to $8 \mathrm{M}$ nitric acid and flush the solids from the tank. The literature indicates that the sooner this is done, the easier it will be to de-polymerize the Pu.

\section{Dip Tube Pluggage in Low Activity Waste Evaporators}

\section{J. H. Gray and R. W. Wainwright}

Solids frequently plugged the Low Activity Waste (LAW) evaporator dip tubes, requiring that the evaporators be shut down and the dip tubes purged with steam before operations resume. Samples were taken from two different evaporators to determine the composition of the solids and how they might be eliminated or avoided.

Samples from the evaporators were essentially identical. The solids were gypsum or hydrated calcium sulfate and the solutions above them contained, not only dissolved gypsum, but also significant amounts of iron. The solids dissolved readily in 4 molar nitric acid, suggesting that the dip tubes can be unplugged by flushing with nitric acid or by increasing the evaporator acidity. However, as long as the LAW evaporator solutions contain calcium ions and sulfate ions, gypsum will form and the dip tube pluggage is likely to continue.

\section{1-H Enriched Uranium Precipitation \\ E. A. Kyser and K. J. Kalbaugh}

Uranyl nitrate solutions, stored in tanks B-3-1 and E-4-2, are sampled periodically to assure that the concentration of dibutyl phosphate (DBP) does not rise enough to cause precipitation of $\mathrm{U}-235$ in the tanks. The DBP is formed slowly by acid hydrolysis of trace amounts of soluble tributyl phosphate in equilibrium with the uranyl nitrate leaving the solvent extraction banks. Previous SRTC work showed that DBP levels up to $100 \mathrm{ppm}$ cause no solid formations. The most recent samples contained 28 and 35 ppm DBP, not significantly higher than results of seven months ago.

\section{HB-Line Direct Support-EP-61 Packaging \\ M. A. Whitney and A. G. Eggers}

Package and Transportation provides support NonConformance Request resolutions, required leak testing, procedure refinement, receiving inspection of 150 new EP-61s and procurement specification for 400 more EP-61s

\section{HB-Line JCO \\ D. P. Eisele}

The HB-Line JCO to support restart of Phase I and III was issued for WSRC approval on August 10, 1992. WSRC approval and transmittal to DOE-SR are expected before the end of August 1992.

\section{RBOF Fuel Slug Retrieval}

\author{
M. Hapstack, R. L. Minichan, and D. C. Patterson
}

A storage canister that stores fuel assemblies in a basin in the 244-H RBOF facility developed a leak and water was allowed to enter. The combination of water and sodium inside the canister generated hydrogen that combined with uranium to form expanding oxides and hydrides in the top portion of the canister. The upper third of the canister split as a result. There is concern that the bottom may not stay intact if the canister is moved in the usual manner. A special device was needed to safely relocate the fuel canister to be shipped to the dissolver and processed.

A canister relocation device, designed by the Environmental Engineering Section, was delivered to the customer. It will secure the fuel canister bottom so the fuel canister can be moved safely. Ring gauges to measure the diameter of the damaged fuel canister were also delivered. A trough is being fabricated to help in the relocation process. An encapsulating device is also being designed. 


\section{PROGRESSAND ACCOMPLISHMENTS}

\section{RBOF Resin Shrinkage}

\author{
E. A. Kyser and A. E. Scott
}

RBOF personnel observed that ten percent less resin came out of the deionizer than the last time it was regenerated. They expressed concem that some resin loss occurred. Resin loading tests in SRTC confirmed the resin manufacturer's literature that describes how much the mixed anion/cation resins shrink upon loading. The volume loss observed at RBOF appears to be due to shrinkage of the resin during loading.

\section{0 \& 9971 Packaging Development for Uranium Solidification Facility and Naval Fuel} G. A. Lucky, R. S. Maurer, and K. M. Stawney

Evaluation of certification test results continue. Fiberboard char depths (decomposition), generated during the thermal event (temperatures of $1850^{\circ} \mathrm{F}$ ), exceeded that considered for the criticality evaluation. Criticality calculations for the measured depths of char will be initiated to determine if this will influence the package capabilities.

\section{2-F Fan Shaft Bearing Rupture Investigation \\ T. E. Skidmore}

On June 18th, 1992 an F-Area Maintenance worker was seriously injured when a fan shaft bearing housing shattered during routine removal, as part of fan mainte- nance. Manual methods proved unsuccessful, so an Enerpac hydraulic tool was used. Upon reaching an unobserved pressure, the maintenance crew decided to cut the bearing from the shaft. Although the pressure on the tool was reduced before the cutting torch was applied, the bearing housing shattered without warning. The largest component, weighing approximately five pounds, flew eight to ten feet and struck the employee in the face. The employee was hospitalized. E\&MT/Materials Consultations failure analysis of the bearing components revealed that excessive pressure applied to the bearing housing stored tremendous energy within the inner race and bearings. Upon reaching a critical pressure, the cast housing fractured to release the stored energy. A final report was issued documenting the metallurgical and programmatic causes of failure, including several recommendations to avoid similar incidents in the future.

\section{Melt Injection System}

\section{L. Skidmore}

Die casting is the process of rapidly injecting molten metal into the cavity formed by two stationary mold halves (or dies). The melt injection system is a slow, hydraulically actuated piston that slides in a cylinder used for testing this critical part of a die casting machine. Casting tests with a bismuth-tin alloy were completed. The casting soundness improved dramatically when the melt injection system was placed in a vacuum chamber. The results of these tests were used to size hydraulic equipment and to refine the design of the melt injection system. The detailed design of the second version of this system was completed and submitted for fabrication. It will be used at LLNL for testing with plutonium. 


\section{PR OGRESS AND ACCOMPLISHMENTS}

\section{ENUIBONMENTAL}

\section{Reactor Restart}

\section{K-Reactor 316(a) Demonstration M.H. Paller}

The procurement package for the K-Reactor Cooling Tower 316(a) demonstration was completed and is being routed for approval and bidding. The revised procurement package allows for a variable study period that will accommodate changes in the duration of $\mathrm{K}$-Reactor operation following start-up in 1993.

\section{Tritium Effluent Monitor \\ Development \\ K.J. Hofstetter}

The tritium effluent water monitor (TEWM) on the outfall from the K Reactor operated for 96 percent of the time during the first 21 days of August 1992. The monitor was off-line for calibration and filter/cell replacements and for an additional 11 hours for a planned power outage. On August 21, the secondary coolant flow was stopped to the $\mathrm{K}-11$ outfall to accommodate the beginning of the cooling tower tie-in efforts. The monitor will remain shut down when there is no secondary coolant flow. When K Reactor was operating, there was no evidence of tritium in the outfall detected by the monitor or by sample analyses. The backup radioactivity monitor, for the existing counting system in the TEWM, is used in the laboratory for calibrating the analysis cells before they are taken into the field and to develop chemical cleaning techniques for used beads.

The improved, second-generation TWEM are field tested at the L-Reactor outfall. The results of the first 25 days of testing showed that the system can operate automatically and provide real-time readouts of the water purification system status. Water quality analyses showed that the system produced water equivalent to distilled water for analysis by the tritium radiation detector. High pressures, or low flows, are sensed by the data acquisition and analysis system and will shut down the system if conditions are outside the control limits. The introduction of spiked samples will confirm tritium sensitivities. These system shakedown tests are necessary prior to the proposed installation parallel to the existing TEWM system on the K-Reactor outfall.

\section{Pen Branch Change Detection Analysis H.E. Mackey}

A draft report documenting the change in vegetation cover in the Pen Branch drainage since 1987 was received from EG\&G, Inc. and reviewed. This document provides revised estimates of acreage affected during K-Reactor operations prior to 1988 and documents the pattern of vegetation succession in the corridor and delta areas of the drainage. The document was returned to EG\&G, Inc. for revision.

\section{Savannah River Swamp Hydrologic Modeling Effort Initiated}

J.B. Gladden and H.E. Mackey

Three parallel efforts to develop the hydrologic model for the SRS Savannah River Swamp were initiated. Topographic surveys of the swamp were begun to aid in developing a digital elevation model. The United States Army Corp of Engineers-Waterways Experiment Station initiated the development of a two-dimensional model of swamp hydrology. Selected SPOT, Inc. satellite data were processed to identify areas of the swamp inundated during various flood-stages of the Savannah River. This latter effort will provide a verification for the hydrologic model. The probabilistic hydrologic model is required to identify areas for swamp revegetation, as specified in the Reactor Operation Environmental Impact Statement Mitigation Action Plan. 
PROGRESS,AD ACCOMPLISHMENTS

\section{Pen Branch Fault (PBF) Confirmatory Drilling}

A. L. Stieve

Twelve holes are complete to date, two of these to basement. The holes were geophysically logged and core description is underway. A piezometer was constructed in one of the deep borings in the Pee Dee formation. Norm Tilford, of the Earth Sciences Advisory Committee, visited SRS to review the status of the project. He visited the field site and core laboratory to review the procedure and progress. He was also provided with a review of the logs and preliminary data interpretation.

\section{Sitewide Environmental}

\section{Recent Charleston Earthquake \\ D.A. Stevenson}

On August 21, 1992 at approximately 12:30 PM EDT (16:30 UTC) a magnitude 4.1 (United States Geological Survey) earthquake occurred in the Charleston, SC area near the town of Summerville, approximately 86 miles southeast of SRS. Reportedly, it was felt by people as far away as Columbia, Aiken, North Augusta, and Augusta, GA. The WSRC/SRTC seismic network recorded the event. In addition, an automatically triggered accelerograph, temporarily installed in the seismic laboratory in 735-11A, was tripped. Preliminary analysis of the accelerograph data indicate small accelerations in the laboratory floor. The last event of similar magnitude to occur in the Summerville area was a magnitude 4.3 earthquake on November 22, 1974.

People in the epicenter area described the earthquake as a large boom accompanied by the rattling of windows and doors, however, no damage was reported. Following the earthquake, Dr. Talwani, of the University of South Carolina-Columbia, requested assistance from WSRC in collecting aftershock data from around the epicentral area. WSRC/SRTC scientists deployed digital event detectors on a farm along the Ashley River and in Old Dorchester State Park. The instruments were left for four days to collect aftershock data. Preliminary analysis of this data indicates no aftershock activity occurred.

\section{Seismic Monitoring D.A. Stevenson}

During August 1992, seismic monitoring at SRS continued with four remote recording stations on site. Noise surveys for sites 5, near Aiken State Park, and 6, near Johnson's Lake were carried out this month. One noise survey remains on a proposed site south of the plant; SRS is awaiting right-of-access to this site. The equipment for the seismic network upgrade from Teledyne Geotech was received this month. It is in temporary storage until installation begins.

Stations are operating with daily record reviews for evidence of localized earthquake activity. The small earthquake reported in last month's report, near Bowman, South Carolina, was more accurately located just west of Neese, South Carolina.

\section{Other Faults Program Plan}

\section{A. L. Stieve}

The program plan for investigating the seismic characteristics of other faults in the vicinity of SRS was submitted to DOE on June 30, 1992. At that time, it was also provided to Earth Sciences Advisory Committee (ESAC) members for their review and comments. Written comments and suggestions were received from DOE and six members of ESAC and verbal comments from one ESAC member. These comments are being addressed and a response will be provided to all parties. Following resolution of these comments the final program plan will be issued.

\section{Par Pond Aerial Gamma Survey Completed \\ H.E. Mackey}

The final overflight in the series of three, was completed on Par Pond. This acrial gamma survey will document the distribution of gamma emitting radionuclides in the exposed surface sediments of Par Pond between 181 feet and 200 feet above Mean Sea Level. The last overflight is being conducted approximately one year after the initial drawdown of Par Pond. Additionally, high 


\section{PROGRESS A ND A C COMPLISHMENTS

altitude photography of Par Pond was obtained opportunistically as the EG\&G, Inc. aircraft was in transit from the East Coast to Nevada.

\section{F/H ETF Biological Monitoring Program \\ W.L. Specht}

A summary report of biological monitoring and toxicity studies for the F/H ETF was completed for submission to the South Carolina Department of Health and Environmental Control (SCDHEC). The results of four years of monitoring studies indicate that the ETF has not adversely impacted the biota of the receiving stream (Upper Three Runs Creek) at the present rate of discharge. Additionally, the effluent is not toxic at the in-stream waste concentration.

\section{Centralized Sanitary Treatment Plan D.W. Hayes, W.L. Specht, et al}

The potential impacts of the construction and operation of the Centralized Sanitary Treatment Plant are being evaluated. Potential conflicts with wetland protection issues and other ecological considerations are being resolved with minor modifications to the project. Initial simulations of effluent impacts using the QUALIIE model, indicate that dissolved oxygen levels in the receiving stream (Four Mile Creek) will be within acceptable levels.

\section{Stream Fisheries Characterization M.H. Paller}

The draft report on characterization of stream fish communities on the SRS were submitted for management review. The report provides current data on the stream fish community structure and environmental correlates for the community structure in SRS streams of varying sizes and types. This report also addresses appropriate methodologies for collecting fish to provide appropriate descriptions of community structure. The last comprehensive survey of
SRS stream fisheries was conducted from 1983 to 1985. This study fills a critical data gap for SRS fish communities information, especially in light of the changes that occurred in SRS operations during the past five years.

\section{Studies of SRS and Plant Vogtle Effluent in the Savannah River W. G. Winn}

Ultra-sensitive radiometric examinations of effluent in the Savannah River were conducted since the initial start-up of Plant Vogtle in 1987. Samples are collected on resin samplers and from river sediments. Primarily gamma-emitting radionuclides were studied in the Underground Counting Facility. Annual reports summarized the findings. The 1991 data were examined and reported in WSRC-TR-92-365. The data shows decreasing radioactive effluent from Plant Vogtle, which is consistent with Vogtle release data. During 1991, gamma-emitting radionuclide concentrations were less than $3 \times 10^{-5}$ of the drinking water guide levels published in DOE 5400.5.

\section{Probabilistic Tritium Dose Estimates D.M. Hamby}

The Environmental Dosimetry Group (EDG) has the capability of estimating distributions of the atmospheric tritium dose received by an offsite individual. A Latin Hypercube random sampling method was used to provide parameter value inputs to the tritium dosimetric model normally used. Nineteen model parameters were assigned distributions characterized as normal, lognormal, triangular, uniform, etc. with ranges covering all possible values. Sensitivity analyses and the affects of correlation of parameter values were also studied. These investigations show that the measured tritium concentration in air, the biological half-life of tritium in the body, and the mass of soft tissue in the body are the parameters to which the model is most sensitive. Additionally, the correlation between input parameters seems to have little affect on the overall dose distribution, even when the degree of correlation is maximized. 


\section{PROGRESSANDACCOMPLTSHMETS}

First Draft of the Radiological Assessment Report on Strontium Published

Evans, Carlton, Murphy, Strom, Geary, and Pinder

The first draft of the Radiological Assessment Program (RAP) document, "Strontium in the SRS Environment", was completed and issued for review. This is the sixth in a series of eight radiological assessment reports dealing with the environmental consequences of the release of specific radionuclides during the course of SRS operations. The earlier documents describe the environmental consequences of tritium, I, U, Cs, and $\mathrm{Pu}$. Documents on $\mathrm{C}$ and $\mathrm{Tc}$ will be published in the future.

\section{Uranium, Cesium, and Plutonium RAP Documents}

W. H. Carlton, et. al.

DOE cleared the RAP documents on Uranium and Cesium in the SRS Environment were cleared for release this month. Corrections are in progress and when references are cleared by DOE, printing and distribution will follow. The RAP document on Plutonium in the SRS Environment is being edited and will be transmitted to DOE by September 21, 1992.

\section{Dosimetry Technical Support and QA D.M. Hamby}

Dosimetry technical support for the site included the review of the Environmental Protection Agency's comments on the $F$ and $H$ area seepage basin risk assessment in preparation for the SRS response, modeling of the metal concentrations at the SRS boundary for a proposed vegetation burn at the SRTC seepage basin, and providing Reactor Materials Engineering \& Technology with the reasoning behind dose factor changes for uranium isotopes. An independent review of the CAP88 atmospheric transport and dosimetry code was obtained from A. A. Simpkins of the Risk \& Source Term Technology Group in the Nuclear Reactor Technology and Scientific Computa- tion Department of the SRTC. Simpkins executed the CAP88 code to attempt to reproduce the results of atmospheric modeling studies of the SRTC effluent stacks. Simpkins' results were identical to previous results obtained by EDG.

\section{GIS Systems Integration}

\section{H.E. Mackey}

SRTC sponsored a tour of the Geographic Information System (GIS) laboratories at the University of South Carolina. The tour was conducted by Drs. Jensen and Cowan and focused on the achievements in integrating various types of remote sensing, GIS, and other digital data in a wide variety of formats across various combinations of hardware and software in a networked computational environments. Representatives from the Environmental Protection Department, Site Development Control and the Mapping Section, the Graphic Information Systems Section, Environmental Restoration Department and the Scientific Computations Section attended the tour.

\section{GIS Data Layers and Remote Sensing Photography Provided H.E. Mackey}

SRTC and EG\&G, Inc. developed ArcInfo Geographical Information System data layers for SRS soils and land cover. They were provided to John Stewart, DOE-EM (HQ), to support a NEPA validation task being developed. Additional tapes of land cover and/or soils were provided to ERD, EPD, and Site Development and Mapping.

Photography support was provided for siting new low-level vaults (Waste Management), for the development of a sampling plan on the uranium distribution in the Tims Branch and Steed's Pond areas (Savannab River Ecology Laboratory), for the Mixed Waste Management Facility (Environmental Restoration Department) and the SRTC seepage basin closures (SRTC), and for Par Pond presentations (SRTC and Engineering and Projects Department). 


\section{New Sanitary Landfill Site Selection}

L. D. Wike, R. K. Aadland, J. S. Haselow

Revised guidance from SCDHEC and the discovery of a discontinuous confining unit at the previously preferred site necessitated that a new site be identified for the new Sanitary Landfill. To date, seven candidate sites were identified for ground-level evaluation and possible geotechnical characterization. The candidate sites were selected based on the presence of upward groundwater pressure gradient, reasonable probability of appropriate geological conditions, and the absence of ecological disqualifying conditions (e.g. endangered species presence). The site selection approach and criteria will be presented to WSRC and DOE-SR Waste Management organizations for confirmation prior to initiation of further geotechnical characterization. Local geotechnical characterization is required before final siting recommendations can be developed for presentation to SCDHEC.

\section{Analysis of NASA Samples from LDEF W. G. Winn}

Fifteen samples associated with the Long Duration Exposure Facility (LDEF) were received for analysis in the Underground Counting Facility using the 90 percent efficient HPGe detector. The concentrations of ${ }^{22} \mathrm{Na}$ in six aluminum samples, ${ }^{\circ} \mathrm{Co}$ in four steel samples, and five tantalum samples were analyzed and reported. Results of these analyses were consistent with previously reported results.

\section{Concentration and Dose Module Added to Advanced Emergency Response System \\ B. L. O'steen, J. D. Fast}

A preliminary concentration and dose module was developed and implemented with an advanced emergency response modeling system. The $3-\mathrm{D}$, time-dependent, flow field and thermodynamic structure of the atmospheric boundary layer is determined by the Colorado State University Regional Atmospheric Modeling System (RAMS). RAMS generates flow and turbulence fields that are used by a companion Lagrangian Particle Dispersion Model (LPDM) to predict contaminant transport. The new module computes the concentration and dose and allows the user to display the results using a 3-D color graphics package. Further modifications will be necessary to include deposition and a more complex dosimetry. A case study of the performance of this system was performed for the July 12, 1992 release of tritium from $\mathrm{H}$ Area. The system produces preliminary results, based on RAMS and LPDM, that were shown to representatives from DOE-Nuclear Production Reactor (Headquarters) to demonstrate its capabilities.

\section{Improvements to Dose Assessment Programs \\ R. J. Kurzeja}

Several computer programs in the Weather Information and Display System (WINDS) were modified to reduce the chance that a user will enter incorrect time and date information. The use of AM or PM was replaced by a 24-hour clock. In addition, the codes check the user entry for reasonableness and displays the user's choice for approval. The most important emergency response codes were modified. The others are scheduled for change so that codes will eventually use the same time and date format.

\section{Five-Year Data Base Frequency Distributions}

\section{A. H. Weber}

Wind direction frequency distributions for the 1987 to 1991 data base show four modes. The first, and most prominent wind direction is from the northeast, two secondary peaks of about the same magnitude occur for winds from the west-southwest and south, followed by a tertiary peak for south-southeast winds. By stratifying the data into daytime, nighttime, and seasonal categories, the contributions to these peaks become more perceptible. The peak from the northeast is caused by greater frequency of occurrence of northeasterlies during autumn and winter, particularly in the midnight and pre-dawn hours. The secondary peak, for winds from the west-southwest, occurs in the moming and mid-day during summer, and the south winds peak comes during the summer and springtime evenings and midnights. The south-southeast peak is associated with summer and springtime evenings. 


\section{PROGRESSANDACCOMPLISHMENTS}

\section{Monitoring of K-Reactor Argon-41 by the TRAC Vehicle \\ J. R. Cadieux}

During K-Reactor power ascension tests, the plume monitor array on the TRAC Vehicle was used to locate the 41Ar plume within a few miles of $\mathrm{K}$ Area. Simultaneous measurements of the integrated gamma-ray background were made with the high pressure ion chamber and showed slight increases ( 0.2 to $0.5 \mu \mathrm{Rem} / \mathrm{hr})$ under the Ar-41 plume. The total background within a quarter mile of the $K$ Reactor during operation was $-9 \mu$ Rem/hr. For comparison, the background at the Augusta Mall entrance, where the TRAC was parked during SRS Appreciation days, was $\sim 15 \mu$ Rem/hr. The satellite Geo Positioning System (GPS) was installed on the TRAC and is operating. The Noble Gas Monitoring System on the TRAC returned to service and was also tested during the TRAC monitoring trips to $K$ Area.

\section{New Production Reactor}

\section{PBF Program}

\section{A. L. Stieve}

Updates on the PBF/Quaternary Investigations, joint programs between NPR and Reactor Restart, are located in the Reactor Restart section of this report (p.33).

\section{Review of Phase III Program Report D. E. Stephenson}

WSRC-NPR received comments and guidance for instructing Law Engineering with technical recommendations to complete the Phase III program report.

\section{|Environmental Restoration}

\author{
Wetland Soils Study Initiated \\ K.L. Dixon, V.A. Rogers
}

Sampling was initiated for the Background Wetland Soils Study. This study, jointly funded with Environmental Restoration, will sample surface soils (<3 m depth) at over 75 locations on and off SRS to establish background concentrations of radionuclides and hazardous/non-hazardous constituents in wetland soils. Sampling was stratified by major wetland soil types. To date, more than two-thirds of the soil samples were collected and sampling is should be completed by mid-September.

\section{TNX Groundwater Remediation}

\section{R. L. Nichols}

SCDHEC and EPA comments on the Interim Action Proposed Plan (IAPP) were reviewed. Work began on the revision of the LAPP and the groundwater characterization report. Groundwater monitoring data from 1988 to 1992 was evaluated and a detailed water table map was prepared.

\section{A/M Area Groundwater Remediation Strom, Nichols, Haselow, Looney, Rossabi, VanPelt, and Jordan}

A subsurface characterization effort near the M Area Basin, using a cone penetrometer as part of the Dense NonAqueous Phase Liquid Investigation Program, was completed. The cone penetrometer successfully collected subsurface information about the lithology of a targeted clay layer in approximately 80 percent of the attempts. Depth discrete Trichloroethylene (TCE) and Tetrachloroethylene (PCE) concentration data were collected during several pushes. This part of the study demonstrated the utility of a 


\section{PROGRESS A ND A CCOMPLISHMENTS}

porous metal sampling port and the pulsed acoustic wave monitor, combined with the cone penetrometer, to inexpensively provide a detailed indication of the distribution of contamination above the water table. The pulsed acoustic wave monitor appears to be a promising broadly applicable instrument for rapid and reproducible measurement of TCE and PCE concentrations (without GC separation) under typical SRS conditions.

\section{F/H Area Groundwater Remediation R.N. Strom}

A soil boring was completed near the $H$ Area seepage basin to provide samples for the clay and colloidal dispersion tests. The tests will provide information for the reinjection of treated groundwater from the area.

\section{Helium Tracer Test to Monitor the Cap at the Dynamic Compaction Test Facility \\ B. B. Looney}

Dynamic compaction, using controlled impacts of a large weight, is proposed as one element in closing low level radioactive waste burial trenches. The compaction operation is intended to compress the waste and to minimize the potential for future subsidence. Such subsidence could compromise the low permeability cover and necessitate long-term maintenance and repairs. Some of the proposed dynamic compaction would be performed in closed and capped areas surrounding a facility, such as the MWMF. Preliminary engineering tests of dynamic compaction in such a setting are planned as a prudent step in the closure process. A Dynamic Compaction Test Facility (DCTF) was constructed to evaluate the compaction process in terms of the compression of waste trenches and potential impacts to nearby facilities. Careful testing and documentation of a clay cap at the DCTF and the effects of the adjacent compaction operations on the cap are important considerations supporting development of final closure plans for trenches surrounding the MWMF. A tracer test, using helium introduced below the cap, was performed to supplement the detailed geophysical monitoring performed by Environmental Restoration. The results of the helium tracer test indicate that helium migrated through the cap during the compaction opera- tions. The migration appeared to coincide with construction seams and/or potential microfracture zones. Following completion of compaction operations, helium monitoring continued and the helium migration ceased. This suggests that the pathways through the clay "healed".

\section{Coal Pile Stud}

\section{R. N. Strom}

Two-dimensional isoconcentration maps of Fe, SO4, $\mathrm{Pb}$ and $\mathrm{Hg}$ concentrations and $\mathrm{pH}$ were prepared for groundwater near the D Area coal pile. These maps differentiate between contaminate sources in D Area, such as the ash-basin and the coal pile.

\section{Office of Technology Development} (OTD)

\section{Integrated Demonstration for Cleanup of Organics in Soils and Groundwater at Non Arid Sites}

Looney, Eddy, Haselow, Hazen, Rossabi, Jarosch, Berry, Kaback, Walton, Bergren, Kin and Barnard

\section{Remediation}

Plans for the dipole radio frequency (RF) demonstration at the A/M Area of the Savannah River Site are progressing well. Sediment samples, characteristic of the sands and clays at the Integrated Demonstration Site (IDS), are being tested to determine the electrical (dielectric constant) and thermal (conductivity and heat capacity) properties. The data generated from these tests will be used in modeling studies to predict the performance of and optimal conditions for the in-situ radio frequency (RF) demonstration that utilizes a dipole applicator. In addition, the first draft of the demonstration test plan was completed and suitable screen and casing material for a second attempt at completing a horizontal well are being evaluated. Consideration is being given to the installation of a vertical well lined with Teflon to provide proof of concept for the dipole RF heating technology for enhanced remediation of Volitile Organic Contaminants from clay lenses. 


\section{PROGRESS AND ACCOMPLISHMENTS}

Operations at the in-situ Bioremediation Test are operating smoothly. Approximately 250,000 and $36,000,000$ cubic feet of methane and air, respectively, were injected as of August 2, 1992. Trace amounts of methane were detected in the extraction well which indicates that the methanotrophs are degrading the TCE. Also, carbon dioxide concentrations increased as a result of the TCE degradation.

\section{Characterization}

A draft report on the results of an aquifer test at the IDS was prepared. The test results indicate that the aquifer is semi-confined with an average hydraulic conductivity indicative of fine to medium grained sand. The results also indicate that the test may have been performed in an area where there is a transition from a semi-confined to an unconfined aquifer.

Interim characterization activities for the bioremediation demonstration were completed on schedule. The objective of this task is to collect characterization data every three months during the in-situ bioremediation to evaluate the effectiveness of the process. These activities included completion of four continuously cored boreholes, two in the zone of influence of the horizontal well and two outside the zone of influence of the horizontal well. Additional samples were collected for geotechnical analysis, including determination of in-situ moisture content of the sediments. Microbiological and analytical analysis of samples is ongoing.

In addition, three SEAMIST liners for depth discrete sampling of the vadose zone were successfully installed at Site 1. The liners monitor the tracer test at the site and will be used for future experiments requiring depth discrete sampling of the vadose zone. Results of the tracer test estimate the consumption of methane in the subsurface during the bioremediation demonstration.

\section{Directional Drilling}

Integrated Demonstration personnel met with Savannah River Environmental Restoration personnel to discuss details of the horizontal drilling demonstration designed to install two horizontal wells in the vadose zone under the M-Area Settling Basin. Two 500 feet screened wells will be installed at a depth of $\mathbf{1 1 5}$ feet. A subcontract is being placed to drill and install these wells; drilling is scheduled to begin in September or October 1992.

\section{TCE Biodegradation (Bioreactor and Vegetation Studies)}

Nutrient utilization tests were conducted to quantify nitrate, phosphate and sulfate consumption in the TNX bioreactor. This information will be useful in optimizing the performance of the microbial degradation process.

\section{Coordination of Metals Bioremoval Research \\ E.W. Wilde}

Visits were made to Lawrence Berkeley Laboratory (LBL) and Oak Ridge National Laboratory (ORNL) to improve coordination in OTD funded bioremoval research efforts. LBL is a co-investigator on the WSRC program (TTP SR-121108) and information exchange on their biochemical and engineering studies proved valuable relative to applications of the WSRC efforts. ORNL is conducting related research and the meeting provided an avenue for coordination and potential future collaboration on the two research programs. 


\section{PROGRESS AND ACCOMPLISHMENTS}

\section{WASTE MANAGEMENT}

\author{
Storage of Plutonium (Pu) in \\ Shipping Containers in the 247-F \\ Facility \\ G. B. Woolsey
}

A formal response to the SAR addendum and OSRs for storage of $\mathrm{Pu}$ in 247-F was received from DOE Separations Division on July 10, 1992. Comments are being reviewed and a written response to DOE is being prepared. A review of plans to store $\mathrm{Pu}$ in 247-F was presented to the Defense Nuclear Facilities Safety Board. The board requested some documents, but no outstanding questions remain. It is possible that additional information will be requested and we will respond promptly.

\section{Materials Testing for Replacement High Level Waste Evaporator (RHLWE)}

\section{G. T. Chandler}

Successive evaporation runs of synthetic waste tank baseline, Purex, and $\mathrm{H}$-Modified solutions were performed to determine the effect of increased temperature on the operating conditions of the RHLWE. Condensed solutions under both operating conditions were allowed to cool after each run to allow precipitation of solids. Under High Level Waste Evaporator (HLWE) operating conditions, six evaporation runs were performed on the baseline solution to obtain a solution with a gravity of 1.5 . The solution hydroxide concentration increased from $1.29 \mathrm{M}$ to $15.1 \mathrm{M}$ and the NO3 concentration decreased from $4.90 \mathrm{M}$ to 0.85 M. Under RHLWE operating conditions, six evaporation runs were performed on the baseline solution to obtain a solution with a gravity of 1.6. The solution hydroxide concentration increased from $1.24 \mathrm{M}$ to $17.7 \mathrm{M}$ and the $\mathrm{NO}_{3}$ concentration decreased from $4.77 \mathrm{M}$ to $0.97 \mathrm{M}$. Solutions from the Purex and $\mathrm{H}$-Modified runs were submitted to $\mathrm{ADS}$ for analysis.

A nickel-based alloy, Hastelloy® G-3, is the replacement for Type 304L stainless steel for construction of the
RHLWE shell. The above evaporation tests will provide information on the operating conditions of the RHLWE that will be used to setup immersion testing of G-3 and $304 \mathrm{~L}$ to determine susceptibility of the materials to corrosion under RHLWE conditions. Also, modifications of the Material Technology Section's (MTS) Constant Extension Rate Test machine are underway to facilitate testing of $304 \mathrm{~L}$ and G-3 for susceptibility to stress corrosion cracking under evaporator operating conditions.

\section{Failure Strain Criteria for the Type III In-Tank-Process (ITP) Waste Tanks}

\section{J. K. Thomas and G. E. Mertz}

Waste Management requested that a task be initiated to evaluate the effects of mechanical property variations and material degradation on the failure strain for the primary liner of the Type IIIA waste tanks to be employed in the ITP process and provide basic mechanical property data to support the waste tank structural analysis. As reported last month, the effects of mechanical property variations and material degradation on the primary liner failure strain were evaluated, and true stress-true strain curves for the primary and secondary liners were developed. A technical report (WSRC-RP-92-859) documenting this work was issued.

The remaining work entails estimating the reduction in liner failure strain, relative to uniaxial tensile test data due to multiaxial loading. The triaxiality factor approach will be employed. This approach was also used to estimate failure strains for the reactor tank and reactor components in the analysis of their response to the gamma heating accident (WSRC-RP-92-304). The triaxiality factor is defined as the ratio of the hydrostatic (mean) stress to the mises (equivalent) stress. Upon first approximation, the failure strain under a multiaxial loading is the uniaxial failure strain divided by the triaxiality factor. A range of triaxiality factors of 1 to 2 is expected for the loadings on the primary and secondary liners. For a deflagration accident in a waste tank, the global failure mode would be over pressurized, therefore, the uniform strain is employed as the failure strain.

The Scientific Computation Section of the Computational Modeling Group performed a finite element analysis of the waste tank for a deflagration accident and they will 
provide the primary and secondary liner stresses required to compute the triaxiality factor with the corresponding strains. The completion date is scheduled for the end of August 1992.

\section{Tank Farm Interim OSR}

\section{J. D. Humphrey and D. L. Kiser}

The first draft of the AJR for the Tank Farm was distributed for comment on July 13, 1992. Comments are expected by July 21,1992 . The interim OSR is expected to be prepared for WSRC internal review by September 16, 1992, which is an "award fee" milestone. Individual OSRs are being written.

\section{Surfynol ${ }^{\text {m }}$ Flammability Investigation M. J. Barnes}

Surfynol $^{\text {th }}$ is a surfactant produced by Air Products that will potentially be used at SRS in ITP, DWPF, and Late Washing operations. The original intended use was as a defoaming agent in the Defense Waste Processing Facility (DWPF) Pump Pits at a recommended concentration of $20 \mathrm{ppm}$. Recently, M. F. Morrissey showed that use at substantially larger concentrations $(500 \mathrm{ppm})$ may result in fewer filter fouling problems.

The objective of this program is to determine if Surfynol ${ }^{\mathrm{N}}$, under Tank Farm radiolytic conditions, would produce flammable gaseous mixtures. Specifically, the production of acetylene from Surfynol ${ }^{\mathrm{m}}$ decomposition is the focus of the program. Acetylene causes concern because of its high degree of flammability. Six main facilities can be impacted by acetylene production: Tank 48, Tank 49, DWPF Pump Pit Tanks, Tank 22, Tank 50, and Filtrate Hold Tanks. Tank 48 and Tank 49 are inerted by a nominal flow of 300 scfm nitrogen. The DWPF Pump Pit Tanks are inerted by a nominal flow of $15 \mathrm{scfm}$ nitrogen. Tanks 22 and $\mathbf{5 0}$ are ventilated with a nominal flow of $300 \mathrm{scfm}$ air.

The calculated amount of acetylene evolved from the tanks would not cause the tanks to exceed the lower flammability limits for acetylene, however, the build-up rate in the event of a loss of ventilation was unacceptably short. Since no data is available on the stability of Surfynol $^{\mathrm{nt}}$ or on the amount of acetylene produced in the decomposition, the calculated values for acetylene concentrations assumed rates that are conservative for radiolytic and chemical decomposition.

These theoretical determinations were deemed unacceptable for an SAR addendum based on the conservatism in the calculations. Two options are being pursued to work around this roadblock, experimental testing to monitor Surfynol $^{\text {N }}$ stability when analytical methodology becomes available and alternative defoamers are being assessed on safety and process concerns in the ITP/DWPF/ Tank Farm environment.

\section{Liquid Radioactive Waste Handling Facilities SAR}

M. J. Ades, D. L. Kiser, S.J. Nathan and S.M. Patel

In support of Chapter 4, several project review meetings were held to define scoping needs for Safety Class Item (SCI) determinations, compliance issues, etc. for development of the SAR.

Safety related criteria that conform to DOE Order 6430.1A for Type I through IV Tanks and the Evaporators were reviewed and the comments were transmitted. Resolution of internal comments on Chapters 5 and 6 drafts is in progress. Chapters $3,4,7,8$, and 9 are being drafted.

\section{Replacement High Level Waste Evaporator (RHLWE)}

K.W. Stephens, D. L. Kiser, S.J. Nathan, and M.J. Ades

A Baseline Change Proposal was submitted to the DOE-SR Change Board to remove the Safety Class designation for the following items on the RHLWE Projects:

- Isokinetic Sampler for the Evaporator Cell

- Evaporator Cell Ventilation System

- Evaporator Cell

- Feed Lines

- Gravity Drain Lines

- Evaporator Jumpers in the Cell 


\section{PR OGRESS AND ACOOMPLISHMENTS}

These items were designated Safety Class before the WSRC policy and SCI methodology was established. Based on the application of the current WSRC methodology, the determination showed that no SCIs are required for the RHLWE. After several meetings, DOE-SR accepted the first two items as non-SCIs, but they are requiring Headquarters acceptance of the WSRC methodology before granting approval on the remainder of the items.

Comments on the Chapter 9 SAR draft, Analysis of Operations for the RHLWE were reviewed with the subcontractor preparing this document. As a result of this meeting and of comments received on the draft, the document was changed to a stand alone Preliminary Safety Evaluation for the RHLWE and will be issued as WSRCRP-92-835. It is anticipated that the document will be issued for WSRC review by October 1992.

\section{Dry Powder Sodium Tetraphenylborate, NaTPB}

\section{J. Barnes}

Gray sediment was found when the storage tanks containing NaTPB solution at Optima (original products of the liquid NaTPB) were emptied. Some concern was raised since the sediment remains unidentified and could possibly foul ITP and/or Late Wash filters. Tests aimed at identifying the gray sediment indicate that the solid is organic in nature. Optima speculated that the sediment was sodium carbonate, however, the solid was insoluble in water and unreactive in nitric acid. Diffuse Reflectance Infrared Fourier Transform spectroscopy and $x$-ray fluorescence spectroscopy were conducted as a means of identifying the solid. Tests were unable to identify the compound, but indicated that it contains bridged phenol groups and could possibly be an organic polymer. No iron compounds were observed (a proven filter-fouling agent) in large quantities. More tests are planned to rule out the presence of small quantities of iron impurities.

Stability tests on NaTPB samples, with and without the gray sediment, indicate that the sediment does not affect the stability of the NaTPB solution. The sediment is an inert impurity. Previous NaTPB samples that decom- posed never formed a similar gray sediment. This indicates that the sediment is probably not a decomposition production but rather a by-product formed during production of the NaTPB.

Since the sediment remains unidentified and may possibly cause filter fouling problems, it was recommended that the sediment be filtered from the solution upon redissolution at Aquafine, Inc. (the company responsible for spray drying, storage, and redissolution of the NaTPB). Filtration was carried out prior to introduction of the NaTPB into current start-up tests.

\section{Benzene Sparging Final Washing Facility}

J. F. McGlynn and L. M. Lee

Interim Waste Technology (IWT) and DWPT are investigating the removal of benzene from wash water in the Late Washing Facility to comply with Tank 22 specifications. Sparging nitrogen through the tank is the option under consideration.

Small scale experiments were performed under the following feed conditions:

- late wash filtrate with surfynol added at room temperature

- late wash filtrate at room temperature without surfynol.

- 1.2 molar $\mathrm{NaOH}$ late wash filtrate at room temperature without surfynol

- 1.2 molar $\mathrm{NaOH}$ late wash filtrate at $50^{\circ} \mathrm{C}$ without surfynol

- 1.2 molar $\mathrm{NaOH}$ late wash filtrate at $50^{\circ} \mathrm{C}$ and increased sparge rate without surfynol

- deionized water at room temperature without surfynol

- deionized water room temperature and increased sparge rate without surfynol

The experimental data was analyzed and results show that sparging can operate at elevated temperatures $\left(50^{\circ} \mathrm{C}\right)$ in the absence of surfynol and at elevated sparge rates. Pilot tests are being planned to support the small scale results. 


\section{PROGRESS AND ACCOMPLISHMENTS}

\section{Reaction of Monosodium Titanate with Acids}

D. D. Walker with L. L. Kilpatrick and A. R. Jurgensen

Monosodium titanate (MST, $\mathrm{NaTi}_{2} \mathrm{O}_{3} \mathrm{H}$ ) reacts with oxalic acid to form water-soluble products when there is sufficient excess acid to keep the pH below 2.0. Excess concentrated sulfuric or hydrocholoric acids also react with MST to yield clear solutions. Formic acid reacts to form water-insoluble products from which the sodium was removed and the titanium content increased. Some conversion to anatase $\left(\mathrm{TiO}_{2}\right)$ occurs. WSRC-RP-92-137 summarizes the information on the reaction of MSTR with acids. This information was compiled for use in studies on cleaning techniques for the in-tank precipitation crossflow filters.

\section{DWPF CCR Recycle Water Impact on F/H ETF \\ M. R. Poirier}

A test program to determine the impact of processing the DWPF Cold Chemical Rum (CCR) recycle wastewater at the Effluent Treatment Facility (ETF) is planned. The ETF is a back-up to the primary wastewater. It backs-up to the primary plan of sending the water to an offsite wastewater vendor. The major ETF issues are cartridge filter effectiveness, Norton filter fouling, organic removal, carbon bed exhaustion, and reverse osmosis membrane performance.

The wastewater simulants will be obtained from the TNX Integrated DWPF Melter System (IDMS). To account for variations in the wastewater, three DWPF simulants will be tested: 100 percent OGCT, 100 percent SMECT, and 50 percent OGCT +50 percent SMECT. Each simulant will be diluted 10:1 with an ETF simulant to examine the impact of mixing CCR and ETF wastewater. The 50 percent $O G C T / 50$ percent SMECT simulant will also be diluted 10:1 with a bacterial containing simulant to look for any synergistic effect between bacteria and the constituents in CCR wastewater.

The wastewater simulants from IDMS will be available between late August and mid-September 1992.
Assuming that the simulants are received as planned, the test work will be completed by October 5, 1992.

\section{Saltstone Disposal Facility}

C.D. Peloso

The comments on the Z-Area SAR were resolved. It was determined that an OSR will be necessary to insure that the facility does not accept high-level waste from its waste generators. The OSR was completed and the SAR and the OSR will be ready for DOE Review by late August 1992.

\section{Transuranium (TRU) Drum Water Intrusion}

L. Williams and D. B. Stefanko

A report summarizing the TRU drum dewatering tests was issued on August 9, 1992. The report documents testing to determine the optimum method or technique for draining rainwater from TRU waste drums.

Two simulated TRU waste drums are undergoing long-term drying tests in conditions similar to storage in the RUBB enclosures. These tests will help define the long-term storage impact of leaving residual rainwater in TRU drums. The moisture will condense on the inner walls of the drums and possibly accelerate corrosion. The drums will be checked periodically for evaporation and condensation and the findings will be documented by September 31, 1992.

\section{Improved Decontamination Customer Orientation}

W. N. Rankin, R. J. Hinds, K. D. Peterson, K. L. Dykes, and P. A. Toole

The Interim Waste Technology (IWT) Decontamination Group initiated a Customer Visitation Program to improve customer orientation. The group is visiting selected customers, approximately every other week, for an informal discussion of program items. The purpose of the visit is to insure that programs meet customers' needs and to identify new customer needs. 


\section{PR OGRESSAND ACCOMPLISHMENTS}

\section{Hazard Waste (HW), Mixed Waste (MW) and Disposal Vaults (DV)}

\author{
L.B. Fatell and G.B. Woolsey
}

The scope of safety analysis required for the hazard and mixed waste disposal facilities was redefined. Changes in the project schedules, for reasons unrelated to safety documentation, changed our priorities. Only the SAR for the low hazard disposal vaults will be pursued in FY93. One possible addition to the work list is a response to the DOE request for a revised Hazard Assessment Document (HAD) for the low hazard vaults. A look at the new proposed inventory shows that the hazard class would not change. Other planned efforts included a Preliminary Safety Analysis Report for the Treatment Building, but a delay in the construction start to 1998 makes work on the PSAR in 1993 unnecessary.

Progress is continuing on the SAR for HW and MW Disposal Vaults Chapters 6 and 10.

\section{Hazard Assessment Documents (HAD)}

M. A. Nadeau and J. M. Pareizs

Environment, Safety, Health \& Quality Assurance approved the SRTC Liquid Waste Treatment Facility HAD, Rev. 1 and the Health Protection Instrument Calibration HAD, Rev. 1, and are reformatting it for issue as technical reports.

Work is being initiated for a HAD of the new Heavy Water Storage Tanks HAD Determination, specifying facility hazards class or indicating no additional hazards, were issued for the following projects:

- project S-4685

- upgrade 2nd Level PA System, Building 221-H, Project

One HAD Determination Screening was performed this month. Thirty-seven HAD Determinations are in various stages of development or review. Since the Hazard Assessment program began, 38 HADs, and $196 \mathrm{HAD}$ Determinations were issued and 40 HAD Determination Screenings were performed.

\section{Safety Analysis \& Hazard Assessment for the New Solvent Storage Tanks J.M. Pareizs}

A Safety Analysis and hazard assessment draft for the New Solvent Storage Tanks was issued to Waste Management Engineering. The tanks will serve as interim storage for spent separations solvent until disposal in the Consolidated Incineration Facility. Potential investigated accidents include: earthquakes, high winds, tomadoes, vehicle crashes, and fires. The analysis shows that the risks associated with solvent storage in the New Solvent Storage Tanks does not represent a significant increase in the risks in the Solid Waste Disposal Facility.

\section{Operational Readiness Review: E-Area Vault Expansion \\ G.B. Woolsey}

Reviews of the Operational Readiness Review Plan for E Area Vault Expansion were held in July 1992. Work continued longer than expected and additional reviews of the security plans are scheduled.

\section{Slurry Pump Improvement Program}

\section{J. R. Brault, E. A. Franco-Ferreira, and J. M. Tarpley}

Interim Waste Technology (IWT) requested Equipment and Material Technology (E\&MT) assistance in bearing design and testing as part of the Slurry Pump Improvement Program.

Long shaft slurry pumps were purchased for use in the tank farm in the early 70's. These pumps have always had problems with the bearings and seals and have undergone several design changes. IWT initiated a program to correct these problems in the existing design and to design a new pump and drive system. Equipment Engineering Section (EES) is providing mechanical design assistance on drive system modifications, fabrication and testing.

The pump was assembled and the data acquisition system was installed. E \& MT will debug and calibrate the data acquisition system. A Pitot tube and a vacuum gage 


\section{PROGRESS AND ACCOMPLISHMENTS}

will be installed on the exhaust ports to monitor pump efficiency. The test procedure is being routed for approval.

\section{Response of a Type III Waste Tank To Benzene Deflagration C. Gong}

For the safety evaluation of Savannah River Site waste treatment operations, benzene deflagration in storage tanks of nuclear wastes is an accident scenario that requires assessment of containment integrity. A quasi-static stress analysis of a Type III waste tank under benzene deflagration was completed. The analysis was carried out numerically with the finite element program ABAQUSD. PATRAN was used for the geometric modeling of the tank complex and post-processing of the results.

Design of a Type III waste tank consists of a primary steel shell in the shape of a torus and a reinforced concrete vault with a center column. The interior surface of the vault is lined with steel plates that are commonly referred to as a secondary liner. The primary and secondary liners are not structurally connected. The primary liner sits on a cement pad on top of the base of the secondary liner. The vertical walls of the liners form two annular spaces, a three-inch space around the column, and a 30 inch space around the outer wall. The top of the primary shell is bolted to the roof slab of the vault. The secondary liner extends horizontally under the roof slab such that the annular spaces are lined with steel plates. The finished tank structure is primarily underground, one or two feet of the vault roof is visible at ground level.

This is a safety margin evaluation instead of a design analysis, therefore care was taken to ensure that the model rigorously represents the real physical system. Sufficient details are considered in geometric and material modeling, such that physical stress concentrations in the structural system are accurately monitored.

Five hundred and fifty one shell elements and 3267 continuum elements are distributed in this model. In addition, 269 slide line interface elements are installed along the gap and sliding surfaces. CRAY used 11 hours of CPU time to complete one set of calculations.
Based on the mechanical properties of the materials used in this tank construction (i.e., steel, ASTM A537 Class 1 for the primary liner AS16 Grade 70 for the secondary liner, reinforced concrete and soil) and the expected stress distribution in the system, elastic-plastic models provide the best continuum description for the materials in this analysis.

The deformation pattern and the stress distribution in the liners indicate that the geometrical and material properties of the tank system can be modeled with ABAQUS to provide a physically viable solution to this problem. The numerical results for the deformation and stress distribution in the steel liners indicate that the primary liner is resistant to at least a 110 psig deflagration pressure and serves as an effective containment shell.

The weakest areas in the primary liner are the bottom one-foot knuckles and the elements on the central column. They show both maximum stress and strain. The maximum true strain is 16 percent at a pressure of $110 \mathrm{psig}$ inside the primary liner.

\section{Full-Scale SRAT/Slurry Mix Evaporator (SME) System Grab Sampler at TNX Utilized to Train DWPF Personnel}

\section{W. John Jenkins}

At TNX ten DWPF Operations personnel were trained on the proper use of the Grab Sampler. Proper operation of the Grab Sampler was first demonstrated by TNX Operations personnel. Then, each of the DWPF personnel was given the opportunity for "hands-on" experience by actually taking one or more samples with the Grab Sampler on the Full-Scale SRAT/SME system. The DWPF Startup Test WP-19 Sampler Study requires the use of the Grab Sampler to take samples from the precipitate reactor-bottoms tank (PRBT), SRAT, SME and MFT during Cold Chemical Runs. 


\section{PR O GRESS AND ACCOMPLISHMENTS}

\section{Full-Scale SRAT/SME System at TNXAt-Line Benzene Monitor for PHA \\ W. John Jenkins}

The testing of the prototype At-Line Benzene Monitor were completed at TNX. This monitor will provide a faster and a more reliable benzene assay of PR samples during DWPF radioactive operation. Statistical Analysis of the test results is in progress to determine the precision and accuracy of the monitor for benzene in pulse-height analyzer (PHA) samples. The At-Line Benzene Monitor was tested with representative Hydragard sampling of benzene in the PHA solution from the full-scale SRAT/ SME system. The precision and accuracy of the PHA benzene assay is essential to implement the DWPF flammability control strategy of limiting the benzene content in the Chemical Process Cell's process vent system. A Process Requirement limits the benzene content of PHA to $30 \mathrm{ppm}$ before the PHA is transferred from the PR into the PRBT. The high volatility of benzene causes concern that a significant loss of benzene vapor could occur from the PHA sample between the time the sample is taken and typical laboratory analysis. The result is a benzene assay that is biased lower than the true benzene content.

\section{Final Assessment of ITP Late Wash on Saltstone}

J. R. Cook, C. A. Langton, E. G. Orebaugh, and E. L. Wilhite

To minimize the formation of ammonium nitrate in DWPF, an extra washing step to remove nitrite is under consideration after ITP. Nitrite is added to Tank 49 as a corrosion inhibitor. The late washing step will result in more radiolysis organics and a more dilute salt solution in Z Area.
A preliminary assessment was completed in May 1992, showing no adverse affect of Late Wash on Saltstone. Properties analyzed in this preliminary assessment included processing properties, compressive strength, leaching properties up to two weeks, TCLP analyses, Z-Area permits, and radiological performance assessments. Waste forms containing one and two times the amount of late wash expected were compared with reference waste forms.

The leaching tests were completed in July 1992 and showed no adverse affect of late wash on saltstone. A final assessment report was issued on schedule to complete this work.

\section{Low Level Radioactive Waste} Disposal Facility (LLRWDF) Dynamic Compaction Unreviewed Safety Question (USQ) Evaluation A. G. Sarrack and N. D. Woody

The Safety Analysis to support the USQ evaluation for proposed dynamic compaction of LLRWDF is complete. A summary letter was issued to Environmental Restoration (ER) discussing the results. A recommendation was made not to compact 40 percent of the area analyzed. A meeting with the 200-Area criticality committee was held to discuss the analysis conclusion and recommendation. The committee will issue a letter to ER recommending further analyses be performed to relax some of the conservatisms used in our analysis. ER may request that this new analysis be performed by SRTC, Nuclear Processes Safety Research, and ER. 


\section{PROGRESS AND ACCOMPLISHMENTS}

\section{GEMERAL}

\section{Organizational Analysis}

P. L. Ames and J. W. Krieger

Organizational analysis is an umbrella term for tasks with the following purposes: improving the quality of organizational data, identifying opportunities for improvement in the organizational structure, and implementing tools to enhance understanding of the organization as it changes. Some tools in the latter category also have potential use for improving communication and coordination among the general employee population.

The Soil Conservation Service (SCS) began demographic presentations following the release of data that ties employee position codes to employment categories (e.g., manager or technical professional). One presentation consists of color pie charts that show employment categories by division. The categories were also used to generate reports on topics such as managers not in charge of any organization, managers without management titles, and managers listed in more than one division.

The release of the employment category data also allowed SCS to improve its method for calculating the span of management. The current method classifies organizations as "soft" or "hard" according to the quality of their data. A soft organization is one with no "children", but includes managers other than the manager of the organization. The method was documented and the results of the calculations were presented to senior management in several formats.

\section{A Relational Database Management System for the Ruth Patrick Science Center at USC Aiken's campus \\ D. Behrens and M. B. McGrath}

A relational database management system for the $R$ uth Patrick Science and Education Center at the University of South Carolina's Aiken campus was completed and implemented. The system was created to manage and track the centers activities and personnel. It also serves to promote technology transfer between the SRTC and University of South Carolina-Aiken and to develop other opportunities for interaction in the application of computing and data process technology. It was developed by Doug Behrens, a high school math teacher from Minnesota who worked with the Scientific Computations Section for eight weeks this summer through DOE's Transient Reactor Analysis Code (TRAC) program.

The system was developed in forth dimension software and runs on a Macintosh computer. Custom menus allow users to directly schedule and manage information on the center's staff, corporate sponsorships, teaching stations, community tours, computer laboratories, teacher workshops, and student tours. Users choose from a variety of options including calendar, tours, workshops, courses, schools, science education enrichment day (SEED), edit records and quick reports.

The calendar option presents a graphical user interface to view or edit events for each day. Personnel are associated with events and the calendar may be printed out and distributed on a daily or weekly basis as a reminder of events. Tours through the center, teacher workshops, some undergraduate courses, and SEED data are scheduled here. Other options include printing reports, form letters for event confirmation, address labels for the correspondences, adding, viewing or editing records and course information, and keeping records of the CSRA schools and contacts.

The Ruth Patrick Relational Management System is an automated methodology to track every activity and person associated with the center. The centers staff find the system invaluable. This project provided a learning base as it expanded our understanding of the center's activities and mission and opened the door for future projects and cooperative efforts between USCA and SRTC.

\section{Mobile Robot Development} R. F. Fogle

Several types of remote controlled vehicles are being developed for use in the Robotic Rapid Response Program. Two of these vehicles are the ACEC and MERRV. Both are skid-steer, battery powered vehicles with nearly 
identical electronic control systems and software. The ACEC vehicle is a tracked vehicle and MERRV is wheeled. Both units are controlled from the same operator console that is contained in an aluminum suitcase. The operator console is portable and was designed for field or building use. It can be powered from a 12 VDC battery or 120 VAC source.

The software for the ACEC and MERRV vehicles was upgraded to permit radio or tether operation. The software will automatically switch from a wire to a wireless mode of operation if the tether link between the operator and vehicle are rendered unuseable. These changes are being documented. Once completed, software development will begin for the upgrades of the Hornet vehicles. Their new electronic control systems are similar to the systems on the ACEC and MERRV vehicles. Many of the codes written for the ACEC and MERRV vehicles can be used in the Hornet software. This should significantly reduce development time.

\section{Cleaning Vanadium Tubing for LLNL}

\section{J. A. Moran}

Pantex will use vanadium tubing to develop a pinch welding procedure in the proposed reuse facility. Any tubing to be pinch welded must be clean to achieve a sound weld. The vanadium was drawn to its present form with no subsequent cleaning. As a result of a tube bore inspection, it was determined that the tubing would require cleaning prior to welding. Due to considerable experience with Nitradd cleaning, it was decided that a variation of this cleaning process would be used to clean the vanadium tubing. The cleaning solution for cleaning vanadium tubing is 12 percent $\mathrm{HNO}_{3}$, eight percent Nitradd, and 80 percent water with an exposure time of five minutes on the pump manifold.

\section{Welding Structural Steel}

\section{B. Young}

The Y-12 implementing procedure for welding structural steel was revised and was routed for comments and approval. At the last welding committee meeting, Design Engineering expressed a desire to adopt this implementing procedure for welding structural steel with some modifications. If an agreement can be reached on the procedure, it will become a WSRC/BSRI implementing procedure. A copy of the procedure is routing to Design Engineering for comments.

\section{Neutron Source Assembly Repair G. D. Teese, J. R. Brault}

The neutron source assembly is a ten curie plutonium beryllium source used for calibration of HP equipment. It is located in a tank filled with heavy water for neutron moderation and shielding. A mechanical drive system moves the source in the tank. However, the drive system is in need of repair.

The system was fabricated and installed in 1961. Custodian copies of the documents, including design details of the sealed drive system, could not be located. An extensive search was initiated as an altemative to design reconstitution. Design drawings were located in an unindexed Vender Print File in Project Central Records.

Loose screws in the drive nut attachment were the cause of the cocking and binding of the nut and the frozen ball bushings. After repair, the system was retumed to service.

\section{SCUREF: Advanced Fracture Mechanics to Assess Complicated Piping Flaws}

P. S. Lam, G. E. Mertz and G. S. Bumgarner

The University of South Carolina completed the J-integral calculations for circumferential cracks under bending for SRS piping. The data base was included in the extended Electric Power Research Institute estimation scheme. A flaw stability analysis, based on the estimation scheme, was demonstrated using a 0.25 inch thick pipe with a mean radius of 7.5 inches. The tensile and fracture properties were selected from the RMP baseline materials reported in WSRC-TR-91-10. The initial half flaw lengths in the circumferential direction were assumed to be 33.25 , $66.5,99.75$ and $133 \mathrm{~mm}$. When the applied bending moment reaches 80 percent of the limit load, there is no crack growth for the first two cases, since the applied J-integral is less than JIC. For the initial half crack length of $99.75 \mathrm{~mm}$, a stable growth of $0.3 \mathrm{~mm}$ was predicted 


\section{PROGRESS ANDACCOMPLISHMENTS}

before crack arrest occurred. In the last case of, $133 \mathrm{~mm}$ flaw length, stable crack growth occurs up to $3.8 \mathrm{~mm}$, beyond which the applied tearing modules (T) is greater than the material $\mathrm{T}$ and unstable crack growth is anticipated. 


\section{ITEMS OF INTEREST}

- K. J. Hofstetter participated in a panel discussion on the impact of nuclear power to future US energy needs at the Ruth Patrick Science Center at USCA. This panel discussion was part of a teacher's workshop on "Teaching Nuclear Topics".

- H. E. Mackey gave the SRS Wetlands Steering Committee a tour of the SRTC remote sensing laboratory.

- Ed Stevens traveled to DOE-HQ in Gaithersburg, Maryland with other Site representatives to provide technical backup for presentations made on low level waste, hazardous waste, and ER road maps.

- Jim Cook, Elmer Wilhite, and Bob Hiergesell attended the meeting of the Performance Assessment Task Team in Santa Fe, New Mexico in August 1992. This included a one day workshop on lysimeters, where Hiergesell reviewed the SRS lysimeter program.

- Ron Hinds attended a DOE workshop at Hanford in August 1992 to update the DOE Decommissioning Handbook.

- K.J. Hofstetter “Aqueous Tritium Monitor Development", Fusion Technology.

- M. H. Paller. "Effects of Artificial Increase in Flow on Fish Assemblages in Two Coastal Plain Streams in South Carolina". Rivers.

- H. E. Mackey. "Predictive Modeling of Cattail and Waterlily Distribution in the South Carolina Reservoir Using GIS Modeling". Photogrammetric Engineering and Remote Sensing (1992).

- D. M. Hamby, R. P. Addis, D. M. Beals, A. L. Boni, J. R. Cadieux, W. H. Cariton, D. L. Dunn, G. Hall, D. W. Hayes, J. D. Heffner, R. Lorenz, M. V. Kantelo, and R. W. Taylor. "Health Impacts of the KReactor Aqueous Tritium Release of December 1991". Health Physics.

- D. M. Hamby. "A Probabilistic Estimation of Atmospheric Tritium Dose." Health Physics.

- $\quad$ R. J. Wolf. "An Atomistic Approach to Uncovering the Behavior of Hydrogen and Helium in Metals". Chemical Design Automation News. 


\section{PRESENTIATIONS}

- $\quad$ R. K. Aadland presented "Hydrostratigraphic Classification of the Aquifer and Confining Units in the SRS Region" to the South Carolina Hydrostratigraphic Subcommittee. The classification and criteria established for classification will be adopted for use throughout the state of South Carolina.

- J. W. Krieger attended the Object World conference in San Francisco, CA. WSRC was one of 15 finalists for a Computerworld Object Application Award. other finalists included General Electric, Boeing, and companies from England, France and Germany. WSRC's entry described the Linkup software developed by the Compliance Management Technology Group.

- J. P. Church attended the National Society of Foundation and Education Council meetings in Chicago, IL. Church is the Secretary and immediate past President of the Scholarship Division of the Professional Engineers Education Foundation.

- T. C. Hazen presented "In Situ Bioremediation Demonstration", at the American Institute of Chemical Engineers Meeting in Minneapolis.

- W. G. Winn's "Evaluation of ${ }^{137} \mathrm{Cs}$ in Pond Sediment with an Underwater HPGE Detector", was accepted for presentation at the ANS Winter Meeting in Chicago, IL in November 1992.

- C. A. Eddy made a presentation at the Technology Exchange meeting in Dallas, Texas, sponsored by the DOE Office of Technology Development.

- P. L. Ames presented CMTs work on span of control to the WSRC Management Action Team on July 7, 1992.

- P. L. Ames presented CMTs findings on Equal Employment Opportunity codes and spans for SRTC at the Organization Analysis Status Review (OASR) on July $9,1992$.

- P. L. Ames presented CMTs work on site organization demographics on July 16, 1992 and the proposed report format at the OASR on July 23, 1992. 


\section{ITEMS OF INTEREST}

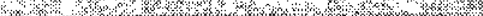

\section{PATENTS}

- P. L. Ames presented the results of senior management interviews at the OASR and J. W. Krieger presented CMTs method for determining organization type and management span.

- M. R. Buckner made a presentation on "Statistical Process Management: An Essential Element of Quality Improvement", at the Westinghouse Electric Company (WEC) Total Quality Management: Metrics of Success III Symposium. Buckner is the SRS representative to the WEC Engineering \& Manufacturing Advisory Council (EMAC) SPC/ SPM User's Group.

- P. Chastagner was awarded a patent for the Thermal Manipulator Medical Catheter.

\section{OTHER}

\section{Scientific Computer Resource Center Courses}

\section{Course}

ORACLE for Developers, Introduction

ORACLE for Developers, Advanced

\section{Students}

10

10

July 27-31, 1992 


\section{Distribution}

\section{DOE-Cermantown}

\author{
J. A. Ford, DP-63 \\ C. G. Halstead, DP-27 \\ R. A. Sanchez, DP-272 \\ S. D. Richardson, DP-60
}

\section{DOE - Forrestal}

C. W. Frank

\section{DOE - SR}

P. M. Hekman, 703-A

M.N. Silverman, 703-A

F. R. McCoy, III, 703-41A

J. R. Patterson, 703-41A

D. N. Bridges, 703-41A

A. B. Sidpara, 703-41A

R. J. Schepens, 704-C

C. A. Everath, 704-C

D. R. Mason, 703-41A

G. Z. Morgan, 703-41A

C. C. Mason, 703-A

D. R. Carpenter, 703-A

S. R. Wright, 703-41A

A. B. Gould, Jr., 703-41A

L. C. Sjostrom, 703-A

A. L. Watkins, 703-46A

\section{S. P. Cowan, EM-30}

R. E. Meadors, DP-27

K. E. Goodwin, DP-636

N. Buschman, DP-636
C. W. Terrell, 704-S

R. L. Chandler, 703-A

R. E. Glass, 703-A

F. W. Caldwell, 703-A

D. R. Spence, 703-46A

L. R. Ogletree, 703-46A

R. K. Franks, 703-46A

S. G. Hortin, 703-46A

J. P. Cohen, 773-41A

E. C. Goodson, 773-41A

U. Y. Park, 773-41A

T. F. Heenan, 703-A

W. J. Brumley, 703-A

M. G. O'Rear, 703-A

L. C. Goidell, 703-A

J.S. Cote, 703-A

J. D. Bilyeu, 703-A

Westinghouse Internal Distribution 


\section{Internal Distribution}

R. T. Begley, 773-A

T. V. Crawford, 773-A

C. G. Hardin, 773-A

L. Papouchado, 773-A

D. C. Richardson, 977-W1

C. R. Wolfe, 773-A

C. W. Smith. 773-43A

J. E. Lunn, 704-1T

R. R. Fleming, 773-A

J. K. Price, 773-A

J. R. Knight, 773-A

W. L. Tamosaitis, 773-A

T. L. Capeletti, 773-41A

N. C. Boyer, 703-A

W. H. Britton, 703-A

R. E. Seif, 703-A

S. T. Goforth, 773-A

S. Giger, 773-43A

M. R. Buckner, 773-A

W. E. Jule, 773-A

A. J. Garreth, 773-A

E. W. Holtzscheiter, 773-A

A. L. Blancett, 773-A

C. E. Coffey, 773-A

D. B. Mocre-Shedrow, 773-A

A. L. Boni, 773-A

J. M. Stogner, 773-A

M. J. Hitchler, 977-W1

O. M. Ebra-Lima, 977-W1

J. C. Corey, 773-A

J. A. Stone, 773-A

J. L. Steele, 773-A

R. G. Davis, 773-58A

J. M. Ferrell, 773-A

M. L. Hyder, 773-A

R. P. Singer, 730-A

C. W. Jenkins, 773-A

M. J. Plodinec, 773-A
D. A. Sharp, 773-42A

W. A. Spencer, 773-A

K. W. Stephens, 977-W1

R. W. Taylor, 735-A

R. R. Beckmeyer, 773-42A

E. J. Majzlik, 730-A

J. T. Carter, 704-1T

F. R. Graham, 773-A

W. R. Wilmarth, 773-A

A. L. Schwallie, 703-A

T. J. Sayers, 703-A

P. D. Rice, 703-A

C. L. Peckinpaugh, 707-C

E. P. Rahe, 703-A

I. B. New, 703-A

P. W. Dickson, 773-A

D. B. Rankin, 704-C

F. Beranek, 773-A

A. F. McFarlane, 773-A

G. H. Clare, 742-3A

C. W. Thiessen, Hitchcock

C. E. Ahlfeld, Hitchoock

F. J. MoCrosson, 773-41A

K. F. Cooper, Hitchoock

J. P. Howell, 773-41A

J. D. Bickley, 723-A

R. Maher, 703-A

J. M. Pope, 703-A

J. V. Cioffi, 730-M

M. F. Sujka, 703-A

C. B. Jones, 704s

J. K. Brown, 703-H

J. T. Buckner, 703-A

V.L. Dorbu, BTC 419

A. E. Hadden, 730-M

J. C. Griffin, 773-A

C. Gurosik, 233-5H

W. P. Mayson, 235-H
D. J. Green, 235-H

V. C. Minardi, 703-A

T. A. Moore, 707-H

J. G. McKibbin, 707-H

J. S. Evans, 707-F

G. T. Wright, 703-H

R. G. Garvin, 703-H

C. R. Sherman, M. Lynch

J. F. Ortaldo, 704-S

S. S. Cathey, 703-H

M. A. Ebra, M. Lynch

W. B. Boore, 707-F

R. W. Harral, 704s

R. R. Campbell, 703-A

D. W. Call, 703-A

J. S. Roberts, 742-A

W. R. Jacobsen, 772-3F

W. C. Reinig, 703-A

J. W. Joseph, 703-A

R. F. Mayock, 979-W

L. J. Hollick, 703-A

S. P. Grotheer, 979-W

L. W. Ice, 703-43A

H. P. Villasor, 703-43A

P. R. Katonak, 773-51A

M. W. Walcher, N. Augusta

T. A. Mangelsdorf, N. Augusta

J. D. Cohen, 730-A

G. A. Krist, 703-A

C. W. Swindell, Jr., 773-41A

R. W. Benjamin, 773-41A

T. H. Gould, 773-41A

W. V. Wright, 773-41A

J. D. Woodward, 703-A

J. B. Schaade, 703-F

R. B. Pagett, 773-56A

B. S. Strack, 773-58A

P. S. Herbert, 723-A

SRL Reconds, 773-A(2) 